\title{
Bond-Based Earthquake-Proof of RC Bridge Columns Reinforced with Steel Rebars and SFCBs
}

\author{
Mohamed F.M. Fahmy ${ }^{1}$ and Zhishen $\mathrm{Wu}^{2}$ \\ ${ }^{1}$ Assiut University \\ 2Ibaraki University, \\ ${ }^{1}$ Egypt \\ 2Japan
}

\section{Introduction}

Bond between reinforcement and the adjoining concrete has been extensively studied, and it is confirmed that the use of deformed bars is essential for composite behavior of reinforced concrete (RC) structures. But since bond between the longitudinal bars and concrete results in concentration of damage at a specific localized interval of longitudinal bars where the local buckling occurs, Takiguchi et al. (1976) suggested mitigating this concentration of damage through unbonding of the longitudinal bars from concrete at plastic hinge zone. Kawashima et al. (2001) conducted an experimental study on RC columns reinforced with different lengths of unbonded bars at the plastic hinge zone. It was noticed that the failure of concrete was much less in the unbonded column than standard column, and strain on unbonded bar was less than that on the reinforcement of standard column. Recently, to improve the seismic performance of RC members, it is highlighted in the study of Pandey and Mutsuyoshi (2005) that reducing bond strength between the longitudinal bars and concrete has a favored effect on the failure mode, shear capacity and ductility of RC bridge piers: failure mode at ultimate state is changed from shear to flexural and shear strength and ductility are increased.

In the performance-based design approach, the design is primarily focused on meeting a performance objective, which is in line with a desired level of service (Floren et al., 2001, Priestley et al., 2007). For instance, new seismic design philosophies for bridges recommend that important bridges subject to massive earthquakes should be able to sustain the expected maximum lateral force in the inelastic stage with limited damages. To achieve this aim, structure should realize the existence of post-yield stiffness, damage level should be limited, and its permanent deformations (residual deformations) should be smaller than a specified limit; and all these indices are essentially dependent on the composite behavior of RC structures. On the other hand, the studies of Kawashima et al. (2001) \& Pandey and Mutsuyoshi (2005) revealed the importance of reducing concrete-to-steel bond to mitigate the concentrated damage in the plastic hinge zone.

In the last two decades, civil engineers and designers have attempted to develop and adopt new forms of materials that would assist in the building of stronger, larger, more longer 
lasting, and aesthetic structures.Because the advantages of advanced composite materials, i.e., fiber reinforced polymers (FRPs), include: light weight, high strength or stiffness-toweight ratios, corrosion resistance, and, in particular, the elastic performance, steel bars hybridized in the longitudinal direction with FRPs were recommended in the study of Fahmy et al. (2010) as an innovative reinforcement method for recoverable structures, where strain-hardening behavior of the innovative bars can be controlled based on both the amount and type of fibers used. Also, the use of the innovative rebars, i.e., steel fiber composite bars (SFCBs), will increase the life spans of structures because the inner steel bar is protected against corrosion (Fig 1). Uniaxial and cyclic tensile behavior of the innovative rebars were experimentally tested by Wu et al. (2010).
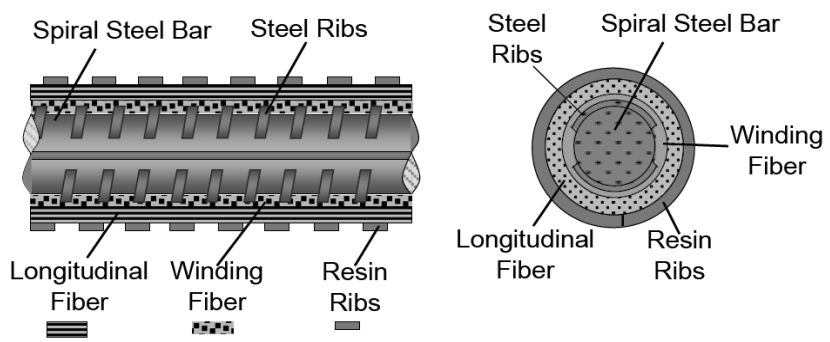

Fig. 1. Details of steel fiber composite bar (SFCB)

Due to the limited studies on bond-controlled structures which are reinforced with the ordinary steel rebars and because of the successful performance of the innovative SFCBs, it is essential to identify a suitable bond-based damage-controllable system, which guarantees limitation of the damage and mitigation of the permanent deformations. In addition, application of this system should not affect the structure load carrying capacity in the inelastic stage: structure should continue able to carrying load in the inelastic stage to withstand strong earthquakes. Hence, in the following, analytical studies using a computer program (Open System for Earthquake Engineering Simulation (Open SEES) [Mazzoni et al.]) are conducted, where effects of concrete-to-steel bond properties on the performance of RC bridge columns reinforced with rebars having different strainhardening levels are determined. Effects of different bond conditions on column elastic and post-yield stiffnesses, residual deformations, and damaged zone are addressed. Validity of the analytical findings is established based on the experimental results of columns reinforced with unbonded deformed steel bars (DSBs) in the plastic hinge zone by Kawashima et al. (2001), columns with bond-controlled reinforcements by Pandey and Mutsuyoshi (2005), and two columns reinforced with rebars having a controlled strain-hardening behavior, i.e. steel fiber composite bars. Ultimately, the influence of concrete-to-SFCBs bond on the recoverability of RC bridge columns is analytically studied.

\section{Idealized load-deformation model of damage-controllable RC structures}

Fig. 2 shows a mechanical model of damage-controllable RC structures located in high seismicity zones. The proposed model exhibits the required performance from newly constructed structures under the effect of different levels of seismic load, where the 
lateral response proceeds along O-A-B-C-D-E-F-G. The behavior of a general RC flexural structure whose lateral response is along $O-A^{\prime}-B^{\prime}-C^{\prime}-D^{\prime}-F^{\prime}$ is also given for comparison. Prior to the yielding of steel reinforcement, lines $\mathrm{OAB}$ and $\mathrm{OA}^{\prime} \mathrm{B}^{\prime}$ corresponding to both types of structures share similar stiffnesses, $K_{1}$. The most remarkable difference occurs after the yielding of the steel reinforcement: after point $C$ and $C^{\prime}$. For the general $R C$ structure, the deformation increases dramatically almost without any significant increase in load carrying capability: along line $C^{\prime} \mathrm{D}^{\prime}$ almost zero post-yield stiffness is demonstrated. However, with the proposed approach, the structure can still carry the load even after the steel reinforcement yields and hardening behavior has been exhibited along line $\mathrm{CD}$. Based on the codes requirements for ductile structures to withstand strong earthquakes, the proposed structure is characterized by the part DEF after the hardening zone, where favorable ductility is demonstrated. The ultimate drift $\left(\delta_{u}\right)$ corresponding to point $\mathrm{F}$ or $\mathrm{F}^{\prime}$ for the proposed structure and the general RC structure, respectively, is defined for both structures to be at 20 percent strength decay, (Park \& Paulay, 1975).

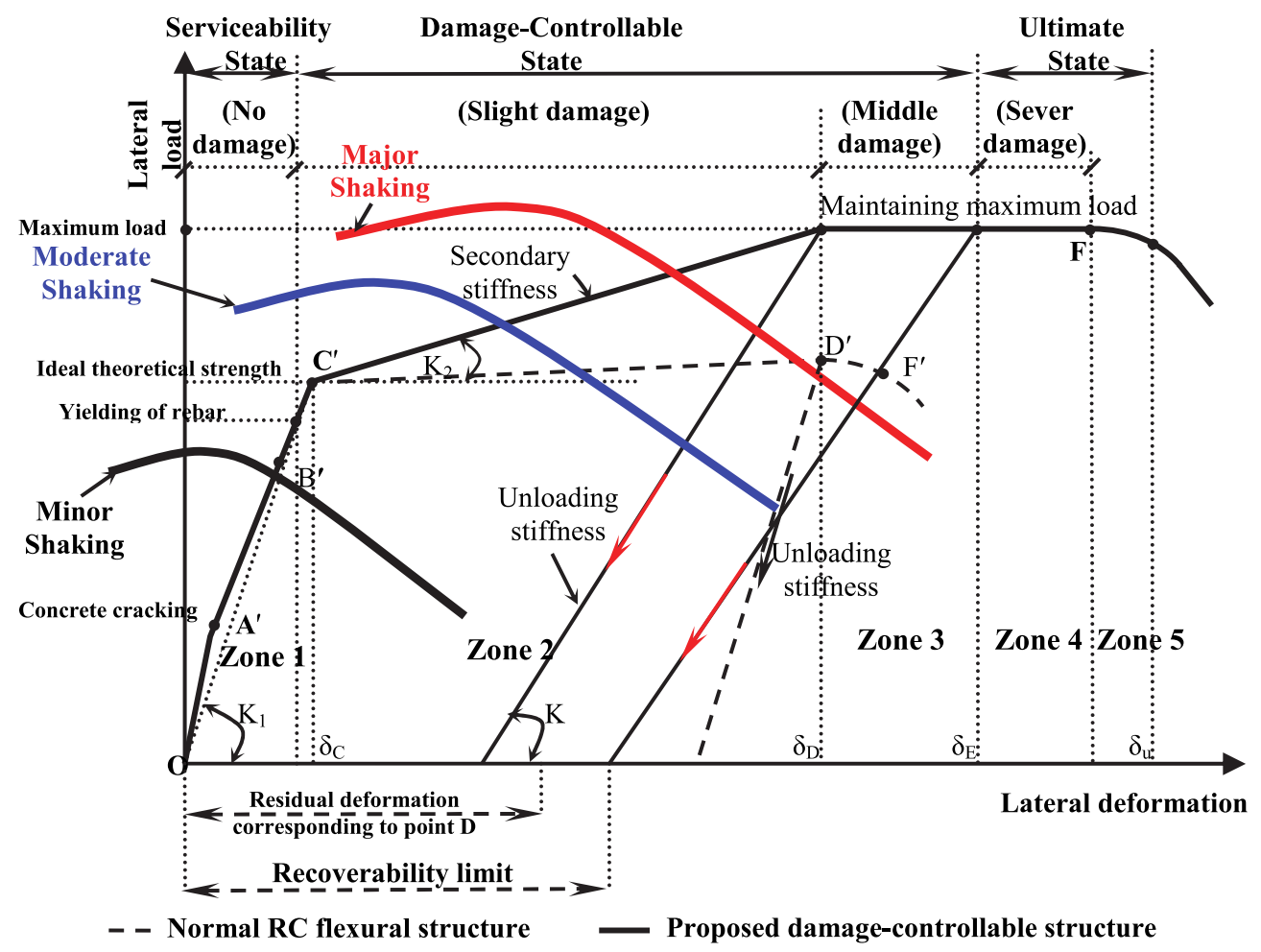

Fig. 2. Idealized load-deformation behavior of proposed damage-controlled structures

According to the mechanical behavior shown in Fig.2, the load-deformation of the proposed structure can be divided into five main zones; Zone 1: from point $\mathrm{O}$ to B; Zone 2: from point $\mathrm{B}$ to $\mathrm{D}$; Zone 3: from point $\mathrm{D}$ to $\mathrm{E}$; Zone 4: from point $\mathrm{E}$ to point $\mathrm{F}$; and Zone 5: after point $\mathrm{F}$. Zone 1 corresponds to a stage of no damage or concrete cracking. Under a 
small earthquake, the mechanical behavior should be controlled in this zone, and the original function of the structure can be maintained without any repair and displacement of elements. Zone 2 corresponds to the hardening behavior after the yielding of steel reinforcements, where a distinct secondary stiffness is demonstrated and the dramatic deformation can be effectively controlled. Under a medium or strong earthquake, the mechanical behavior of the proposed structure should be within zone 2 . Thus, damage can be effectively controlled by the secondary stiffness. The original function of the structures can be quickly recovered through repairs after a medium or large earthquake. Zone 3 corresponds to ductile behavior after hardening, where favorable ductility is demonstrated under a large earthquake but with middle level of damage. Furthermore, within this zone structure should be recoverable, where residual deformation does not exceed recoverability limit, i.e. residual deformations should be less than $1 \%$ of structure height for quick recovery of original functions of structure after an earthquake. Zone 4 corresponds to additional ductile behavior, where the proposed structure can be kept in place without collapse during a large earthquake, though severe damage may occur. The original function of the structures may be recovered through the replacement of some elements. During a severe earthquake, the mechanical behavior may enter zone 5 with collapse.

It is clear that two indices should be applied to measure the recoverability of RC structures: secondary stiffness and residual deformation. However, to have a complete description of structure performance, damage level should be considered in the evaluation of the recoverability of structures after seismic excitation. In the study of Mostafa (2011) several damage measures based on a single response parameter are summarized.

\section{Analytical investigation}

Of crucial importance in the anti-seismic design of RC bridges is to ensure the gradual increase of strength after yielding (existence of positive post-yield stiffness) and to minimize the permanent deformation due to a massive earthquake so that the damage can be easily repaired. That is quickly recoverable bridges after sever seismic actions. In this study mechanical properties of steel reinforcement used and its bond conditions to the surrounding concrete are key parameters to investigate how could be the required recoverability of $\mathrm{RC}$ bridges controlled? Thus, in the following section, analytical studies are carried out to detect their effects on the performance of RC columns: elastic and post-yield stiffnesses, residual deformations, and damage level.

\subsection{Fiber-based model of RC columns with zero-length section element}

Cyclic loading analysis is conducted using a computer program (Open SEES) [Mazzoni et al.]. This program has a variety of predefined material models for multiple applications that can be manipulated to fit specific criteria and properties. Since the fiber analysis remains the most economic and accurate means to capture seismic behavior of concrete structures (Spacone et al. (1996) and Saiidi et al. (2009)), the fiber model was used, Fig. 3. The confined concrete properties were based on Kent-Scott-Park's model. The widely used GiuffréMenegotto-Pinto model is employed in this study to represent the hysteretic stress-strain behavior of longitudinal steel reinforcement. The model includes the yielding, strain hardening, and Bauschinger effect of the steel bar. 


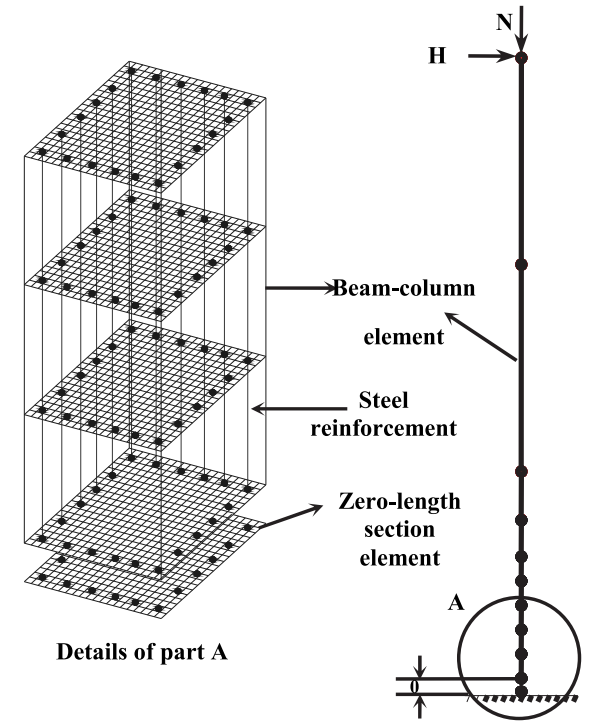

Fig. 3. Fiber-based modeling of the studied columns

Zhao \& Sritharan (2007) have developed fiber-based analysis of concrete structure through the incorporation of a zero-length section element to reflect the effect of the fixed-end rotation that arises at the column-foundation or column-beam interface on the performance of structures. The conducted analyses by Zhao \& Sritharan (2007) on cyclic responses of cantilever columns and a bridge tee-joint system, satisfactorily captured deflections, force versus displacement hysteresis responses, and strains in the longitudinal reinforcing bars. The developed constitutive model by Zhao \& Sritharan (2007) for the steel fibers of the zerolength section element expresses the bar stresses $(\sigma)$ versus loaded-end slip $(S)$ response. The main parameters of this model are the loaded-end slips $S_{y}$ and $S_{u}$ and their corresponding bar stresses $\sigma_{y}$ and $\sigma_{u}$, respectively. Incase the bar has a sufficient anchorage length, $f_{y}$ and $f_{u}$ are the stresses corresponding to $S_{y}$ and $S_{u}$, respectively, where $f_{y}$ and $\mathrm{f}_{\mathrm{u}}$ are the yield and ultimate strengths of the steel reinforcing bar, respectively, Fig. 4(a). Zhao \& Sritharan (2007) defined that the sufficient anchorage length is not less than $\left(\left(d_{b} / 7\right)\left(f_{y} /\left(f_{c o}^{\prime}\right)^{0.5}\right)\right.$, where $d_{b}$ is the bar diameter $(\mathrm{mm})$ and $f_{c o}^{\prime}$ is the concrete compressive strength in MPa. To determine the suitable value of $S_{y}$, Zhao \& Sritharan (2007) proposed the following experimentally-based equation:

$$
S_{y}=2.54\left[\frac{d_{b}}{8437} \frac{f_{y}}{\sqrt{f_{c o}^{\prime}}}(2 \alpha+1)\right]^{1 / \alpha}+0.34
$$

where $a$ was taken as 0.4 . Definition of $S_{u}$ value is based on the determined value of $S_{y}: S_{u}=$ 30 40 $S_{y}$. This model is employed for capturing the slip effect in flexural members subjected to reversed cyclic loading, and hysteretic rules were established, Fig. 4(b). Consequently, this model is adopted here to find out the impact of different bond behaviors on the performance of cyclically loaded RC columns. 


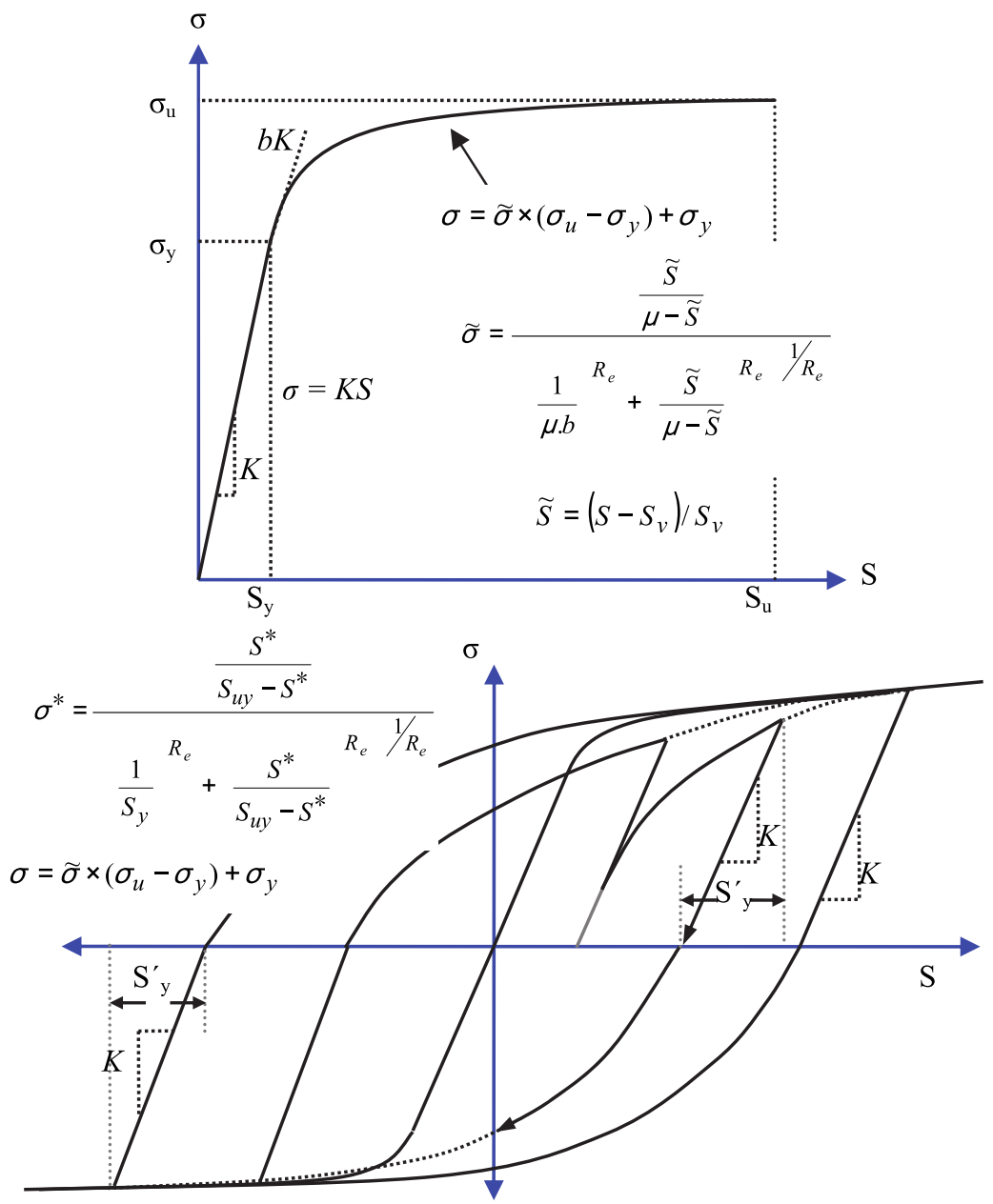

Fig. 4. (a) Envelop curve and (b) Hysteretic model for steel bar stress versus loaded-end slip relationship (Zhao \& Sritharan, 2007).

\subsection{Effect of bond parameters and rebar mechanical properties on the performance of RC column}

Kawashima et al. (2001) conducted an experimental study on four RC columns (A, B, C, and D). Specimen A was tested to simulate the performance of conventionally reinforced column but the others were reinforced with bars unbonded at the plastic hinge zone. Here, hysteretic response of Specimen A is considered as a control sample to find out the effects of different bond conditions between column reinforcement and the surrounding concrete on its hysteretic performance (in particular the required recoverability). The tested specimen had square crosssection of $400 \times 400 \mathrm{~mm}$ and $1450-\mathrm{mm}$-height. It was reinforced with twelve longitudinal rebars of 13-mm-diameter of $367 \mathrm{MPa}$ yield strength, lateral reinforcement consisted of 6-mm-diameter ordinary rebars with yield strength of $376 \mathrm{MPa}$ and spacing of $50 \mathrm{~mm}$. The tested compressive 
strength of the concrete cylinder was 20.6 MPa. The column was tested under constant axial load $(160 \mathrm{kN})$ and reversed cyclic lateral load. Using the four parameters of Zhao and Sritharan model $\left(\left(S_{y}\right.\right.$ and $\left.\sigma_{y}\right)$ and $\left(S_{u}\right.$ and $\left.\left.\sigma_{u}\right)\right)$, ten different bond conditions are studied (Table 1$)$.

\begin{tabular}{|c|c|c|c|c|c|c|c|c|c|}
\hline \multirow{2}{*}{$\begin{array}{l}\frac{5}{5} \\
\frac{0}{0}\end{array}$} & \multirow[b]{2}{*}{ छ্ } & \multirow[b]{2}{*}{ Column } & \multicolumn{3}{|c|}{ Steel mechanical properties } & \multicolumn{4}{|c|}{ Bond properties } \\
\hline & & & $\begin{array}{c}f_{y} \\
(M P a)\end{array}$ & $\begin{array}{c}f_{u} \\
(\mathrm{MPa})\end{array}$ & $E_{2} / E_{1}$ & $\begin{array}{c}S_{y} \\
(\mathrm{~mm})\end{array}$ & $\begin{array}{c}\sigma_{y} \\
(\mathrm{MPa})\end{array}$ & $\begin{array}{c}S_{u} \\
(\mathrm{~mm})\end{array}$ & $\begin{array}{c}\sigma_{u} \\
(\mathrm{MPa})\end{array}$ \\
\hline \multirow{3}{*}{$I$} & 1 & $0.01-S_{y}-0.8 f_{y}$ & 367 & $1.5 f_{y}$ & 0.01 & $S_{y}$ & $f_{y}$ & $S_{u}$ & $0.8 f_{y}$ \\
\hline & 2 & $0.01-2 S_{y}-0.8 f_{y}$ & 367 & $1.5 f_{y}$ & 0.01 & $2 S_{y}$ & $f_{y}$ & $2 S_{u}$ & $0.8 f_{y}$ \\
\hline & 3 & $0.01-3 S_{y}-0.8 f_{y}$ & 367 & $1.5 f_{y}$ & 0.01 & $3 S_{y}$ & $f_{y}$ & $3 S_{u}$ & $0.8 f_{y}$ \\
\hline \multirow{2}{*}{ II } & 4 & $0.01-S_{y}-f_{y}$ & 367 & $1.5 f_{y}$ & 0.01 & $S_{y}$ & $f_{y}$ & $S_{u}$ & $f_{y}$ \\
\hline & 5 & $0.01-2 S_{y}-f_{y}$ & 367 & $1.5 f_{y}$ & 0.01 & $2 S_{y}$ & $f_{y}$ & $2 S_{u}$ & $f_{y}$ \\
\hline \multirow[t]{2}{*}{ III } & 6 & $0.01-S_{y}-1.5 f_{y}$ & 367 & $1.5 f_{y}$ & 0.01 & $S_{y}$ & $f_{y}$ & $S_{u}$ & $1.5 f_{y}$ \\
\hline & 7 & $0.02-S_{y}-2 f_{y}$ & 367 & $2.0 f_{y}$ & 0.02 & $S_{y}$ & $f_{y}$ & $S_{u}$ & $2 f_{y}$ \\
\hline \multirow[t]{2}{*}{ IV } & 8 & $0.04-S_{y}-2 f_{y}$ & 367 & $2.0 f_{y}$ & 0.04 & $S_{y}$ & $f_{y}$ & $S_{u}$ & $2 f_{y}$ \\
\hline & 9 & $0.08-S_{y}-2 f_{y}$ & 367 & $2.0 f_{y}$ & 0.08 & $S_{y}$ & $f_{y}$ & $S_{u}$ & $2 f_{y}$ \\
\hline$V$ & 10 & $0.12-3 S_{y}-1.5 f_{y}$ & 367 & $2.5 f_{y}$ & 0.12 & $3 S_{y}$ & $f_{y}$ & $3 S_{u}$ & $1.5 f_{y}$ \\
\hline
\end{tabular}

Note: $E_{1}=200 \mathrm{GPa}$

Table 1. Reinforcement mechanical properties and corresponding bond properties

To evaluate the effect of the strain-hardening behavior of steel reinforcement used on the performance of bond-controlled structures, five values of the bilinear ratio factor $\left(r=E_{2} / E_{1}\right)$, where $E_{2}$ and $E_{1}$ are the steel elastic and post-yielding stiffnesses, are examined here, i.e. $r=0.01$, $0.02,0.04,0.08$, and 0.12 . Of course bond between reinforcement and the adjoining concrete is an essential factor in the definition of both $\sigma_{y}$ and $\sigma_{u}$ and the corresponding slip values. Therefore, five groups (I, II, III, IV, and V) are studied here, Table 1. The groups I, II \&III consider the effects of bond parameters on the performance of columns reinforced with ordinary rebars (bilinear ratio factor $=0.01$ ). In case no. 6 of group III, bond parameters are those proposed by Zhao \& Sritharan (2007) to include the effect of strain penetration of longitudinal bars into foundation on the lateral response of conventionally RC columns. Meanwhile, the aim in the groups I and II is to characterize the effect of weak bond strength between ordinary rebars and concrete, so, it is assumed that rebars may not approach the ultimate strength, e.g. $\sigma_{u} \leq f_{y}$, and also $S_{y}$ would increase to two or three times of its value evaluated based on Eq. 1. Effect of higher bilinear ratios of steel reinforcement is examined in the last two groups (IV and V). In group IV, the ultimate strength of rebars used is kept constant $\left(2 f_{y}\right)$ while different bilinear ratios $(r=0.02,0.04$ and 0.08$)$ are studied. In the last case study (group $(\mathrm{V}))$, column is reinforced with rebars having bilinear ratio factor of 0.12 but it is assumed that, through controlling the bond conditions, rebars may not approach more than $60 \%$ of their ultimate strength along with the effect of additional slippage. It is noteworthy that the studied cases of RC columns are typified based on the bilinear ratio between post-yield and elastic stiffnesses of steel reinforcing bar, rebar loaded-end slip at $\sigma_{y}$, and maximum achieved strength of reinforcing steel at the ultimate slip $\left(S_{u}\right)$ of rebars. For instance, $\left(0.01-2 S_{y}-0.8 f_{y}\right)$ is the designation of case two of group I, where 0.01 is the bilinear ratio factor of reinforcing steel; $2 S_{y}$ is double of rebar slip value calculated by Eq. 1 and $\sigma_{y}$ is the corresponding strength; and $0.8 f_{y}$ is $80 \%$ of rebar yield strength, which is considered the maximum achieved strength $\left(\sigma_{u}\right)$.

Hysteretic responses of the studied cases are depicted in Fig. 5, wherein the measured forcedrift relationship of Specimen A is superimposed for comparison. 

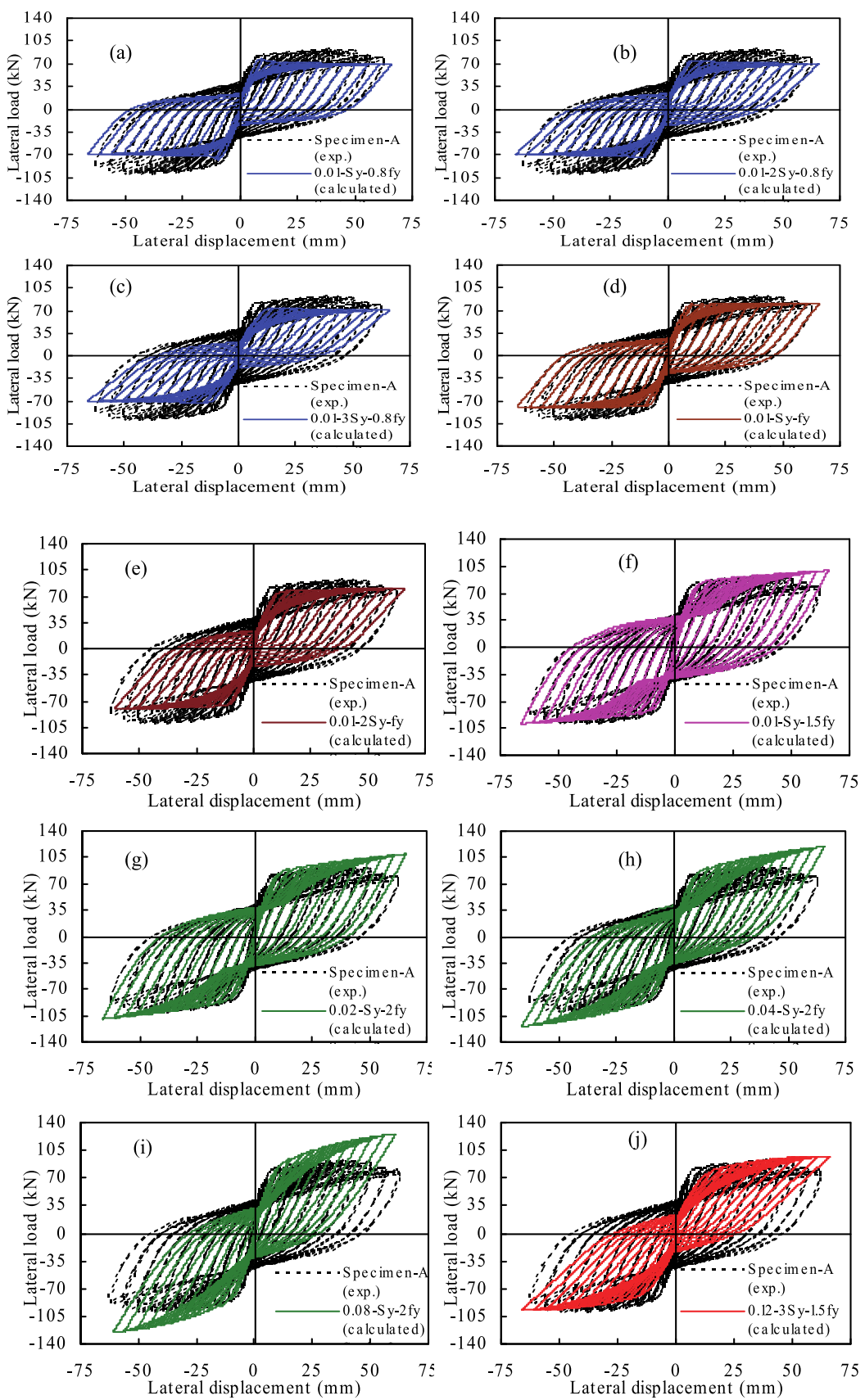

Fig. 5. Effect of bond properties on the hysteretic responses of RC bridge columns reinforced with rebars of different levels of strain-hardening 


\subsubsection{Detailed discussion on bond-based performance of RC columns}

In the light of the aforementioned analytical results, this section presents a detailed discussion about the effects of altering bond conditions and steel type on the performance of RC column in terms of its post-yield stiffness, residual deformation, and damage level.

\subsubsection{Post-yield stiffness}

The post-yield stiffness is defined as the gradual increase of column strength after fulfilling its theoretical moment capacity $M_{i}$, and the end point of the post-yield stiffness is that corresponding to the maximum lateral capacity. The theoretical moment capacity is calculated using ACI rectangular stress block for concrete in compression, which has a mean stress of $0.85 f^{\prime}{ }_{c o}$, the measured concrete compression strength $f^{\prime}{ }_{c o}$ and steel yield strength $f_{y}$, and an ultimate concrete compression strain of 0.003 [ACI 318-08]. Based on the specified details, dimensions, and material properties of the tested specimen A, theoretical ideal strength $\left(P_{i}=M_{i} / L\right.$, where $L$ is column height) is defined and superimposed in Figs. 6 (a-d). Figs. $6(\mathrm{a}-\mathrm{d})$ show the skeleton curves of the hysteretic responses of the analytical studied cases.

The experimental results of the conventionally tested column (Specimen A) showed that column was able to carry the load even after achieving the theoretical strength $(84.4 \mathrm{kN})$ and hardening behavior has been exhibited. The envelope of the measured force-drift relationship of Specimen A is superimposed on the results of the studied cases, as shown in Figs. 6 (a-d). The curves are the average of the envelopes for the push-and-pull loadings. It was reported by Pettinga et al. (2006) that systems exhibiting post-yield stiffness ratios greater than $5 \%$ will have significantly reduced permanent displacements. The ratio between column post-yield stiffness $\left(k_{2}\right)$ and elastic stiffness $\left(k_{1}\right)$ of Specimen A is $2.35 \%$. Accordingly, to achieve the aim of quickly recoverable bridges after massive earthquakes, an enhancement of the performance of conventionally RC column is still necessary.

When weak bond strength between ordinary rebars $(r=0.01)$ and the surrounding concrete is considered, the analytical results show that the column performance in the inelastic stage is function of reinforcement stresses at the ultimate slippage, Figs. 6 (a \& b). For instance, in the studied cases of group I, where reinforcement stresses would not exceed $80 \%$ of the yield strength, column deformation increases dramatically with a decrease in the load carrying capability after yielding (negative post-yield stiffness), Fig. 6 (a); but, In group II, zero postyield stiffness is the column performance in the inelastic stage when reinforcement stresses would approach the yield strength at the ultimate slippage, Fig. 6 (b). It is noteworthy that, in both groups, columns could not reach up to the theoretical strength of Specimen A.

As is clear from Fig. 6 (c), replacement of ordinary rebars with others, having higher strainhardening levels and perfect bond to the surrounding concrete, would enhance column performance in the inelastic stage. Where the increase in $r$ value leads to an increase in column post-yield stiffness, e.g. the ratios between column post-yield and elastic stiffnesses $\left(k_{2} / k_{1}\right)$ are $2.88 \%, 4.05 \%$, and $5.2 \%$ when steel bilinear ratio are $0.02,0.04$, and 0.08 , respectively. It should be noted that the first stiffness was the same among the studied cases and Specimen A, as shown in Fig. 6 (c).

In the last case study, where $r$ is 0.12 , although merely $60 \%$ of rebar ultimate strength could be achieved along with an increase in rebars slippage, Fig. 6 (d) shows that columns could realize the existence of post-yield stiffness $\left(k_{2} / k_{1}=3.18 \%\right)$ and reach up to the same lateral strength of specimen A. Moreover, in a distinction from the other studied cases, a third zone with zero post-yield stiffness characterizes the inelastic stage of this column. 
It is noteworthy that the slope of column elastic stiffness would slightly affect by the increase in rebar slippage at yielding when it is double of the value calculated from Eq. 1, Figs. 6 (a \& b); however, it decreases to two-third of the elastic stiffness of conventionally RC column when rebar slippage increases to $3 S_{y}$, regardless of whether the bilinear ratio is small or high, Figs. 6 (a \& d). The lower stiffness of the columns would lead to longer vibration period for the columns and would generally reduce earthquake forces (Saiidi et al. (2009)).
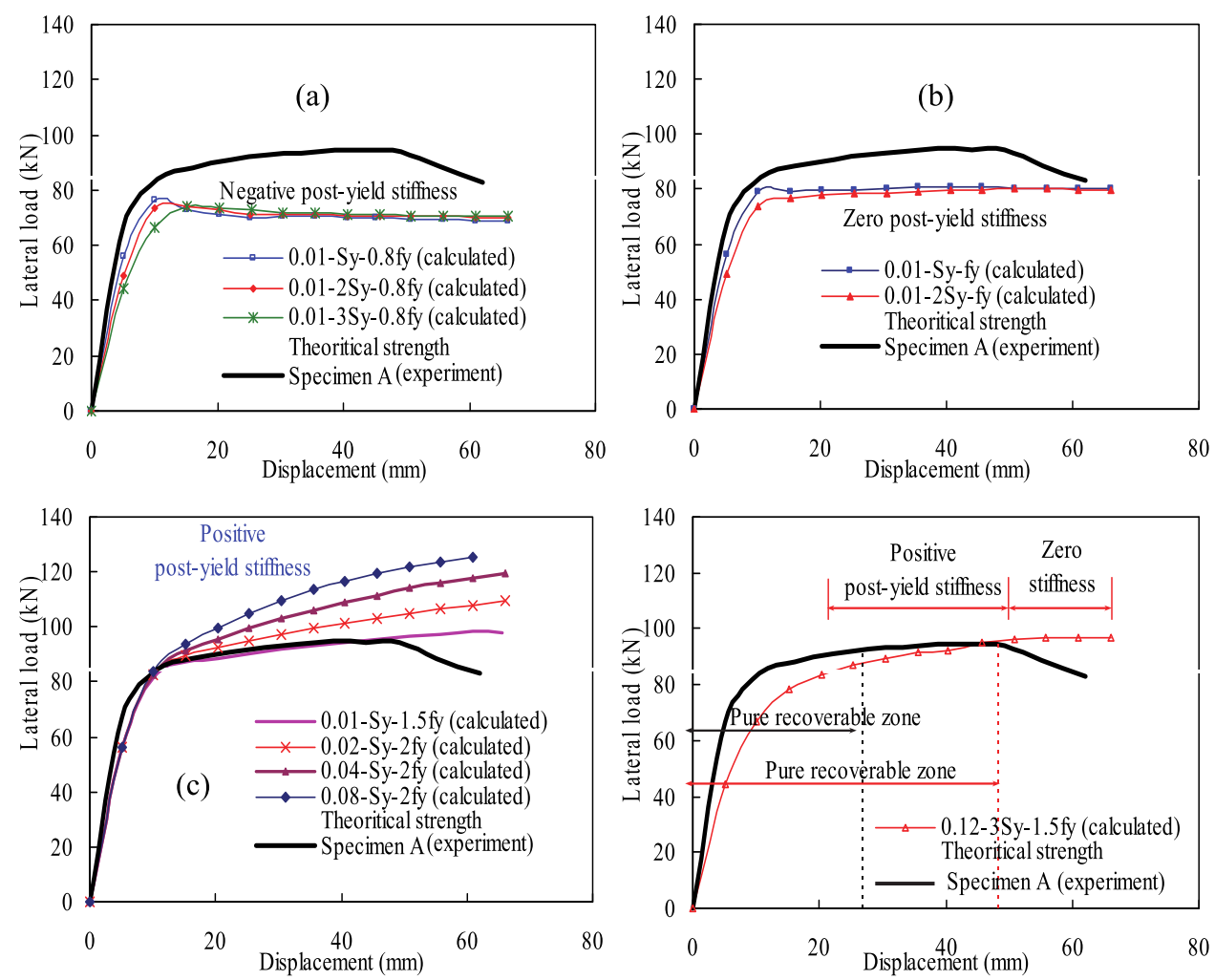

Fig. 6. Effect of bond properties on the post-yield stiffness of RC bridge columns reinforced with rebars of different levels of strain-hardening

\subsubsection{Residual deformations}

Using the test results of specimen A and analytical results of the studied cases (Fig. 5), the drift ratios versus columns residual drift ratios are plotted in Fig. 7. The residual deformation, which is defined as the displacement of zero-crossing at unloading on the hysteresis loops, should not exceed $1 \%$ of the column height for a quick recovery after an earthquake (JSCE, (2000)). For specimen A, the drift ratios versus residual drift ratios are superimposed on Figs. 7 (a-d) for comparison. While specimen A was able to reach up to $4.6 \%$ lateral drift ratio with almost $12.1 \%$ strength decay, the end of the recoverable stat is corresponding to $1.83 \%$ lateral drift, Fig 5 (d) \& Fig. 7. After lateral column drift of $1.83 \%$, 
regardless of whether damage level is light, medium, or sever, column can not continue to function following major earthquakes and demolishing may be required. Consequently, mitigation of column residual deformations is critical to have ductile-recoverable bridges.

Figs. 7 (a \& b) present the residual drift ratios verses lateral drift ratios of columns with different levels of bond capacity between ordinary rebars and the surrounding concrete. As is clear, mitigation of column residual deformation is in direct relationship with rebar slippage, where the increase in rebar slippage to two and three times of the value defined by Zhao \& Sritharan model shifts the recoverable zone by almost $0.5 \%$ and $1 \%$ lateral drift, respectively.

The effects of using reinforcement with high bilinear ratio $(r)$ on column residual deformations are shown in Fig. 7 (c), where a favorable effect could be noticed. For example, $2.16 \%$ lateral drift is the end of the recoverable state of column reinforced with rebars of 0.02 bilinear ratio factor; and when the bilinear ratio increases to 0.04 and 0.08 , the end of the recoverable stat is shifted to $2.38 \%$ and $2.67 \%$, respectively. Furthermore, Fig. 7 (d) exhibits the effect of using rebars with a higher bilinear ratio $(r=0.12)$ coupled with the effects of weak bond strength to the adjoining concrete. The simulation results indicate that column performance is ductile-recoverable, where column could be recoverable until lateral drift ratio of $3.34 \%$ with the existence of post-yield stiffness, as shown in Fig. 6 (d).
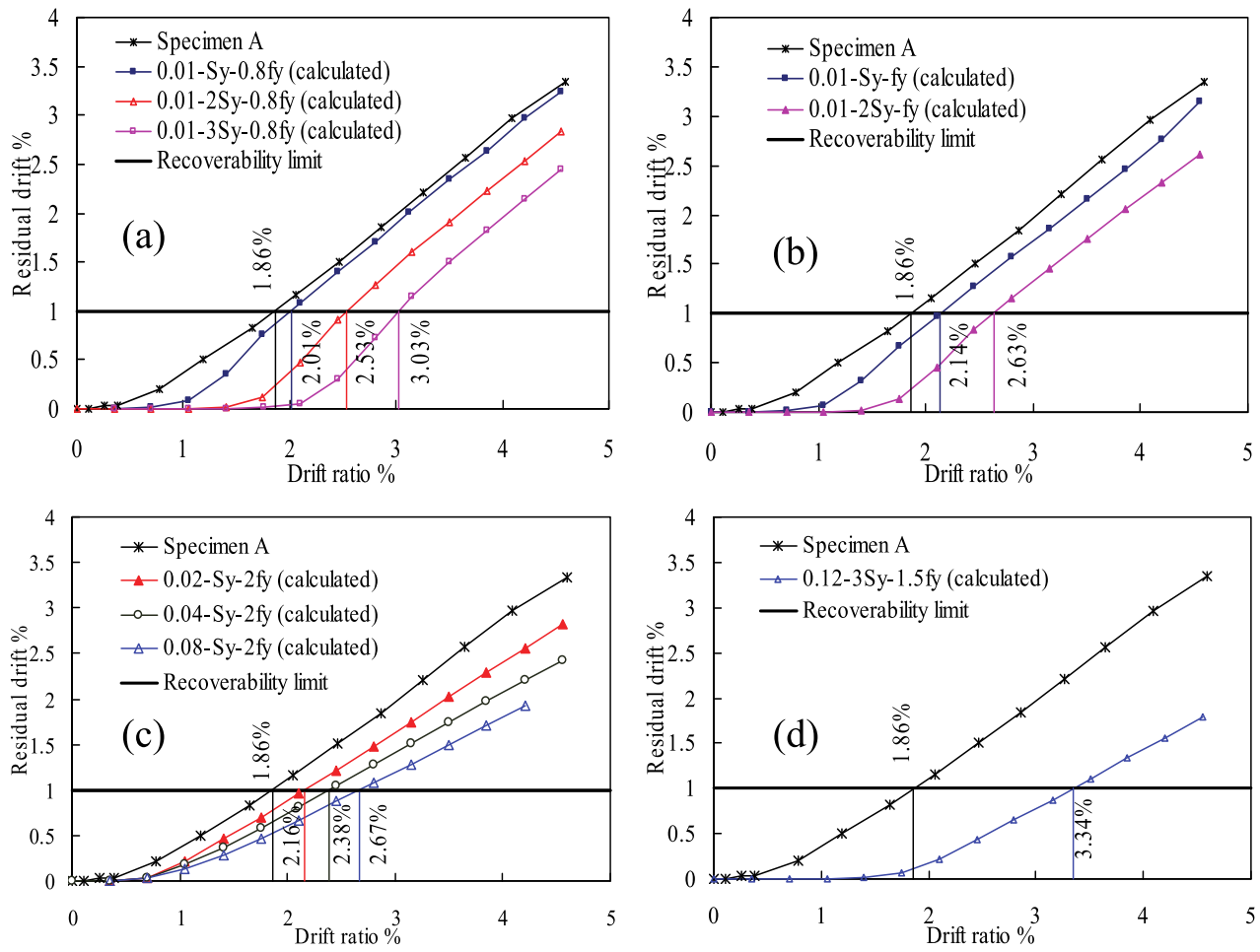

Fig. 7. Effect of bond properties on the residual deformations of RC bridge columns reinforced with rebars of different levels of strain-hardening 


\subsubsection{Damage level}

The main conclusion taken from the aforementioned analytical results presented in Figs. 6 and 7 is that both steel strain-hardening behavior and concrete-to-rebar bond capacity are key parameters, which can be employed to achieve the required performance from structures during and after seismic actions. Even so, to define a suitable system guaranteeing the aim of damage-free recoverable structures, investigating the effects of the studied parameters (Table 1) on column damage level is indispensable. The literature on damage measures of structures under ground motions is vast (e.g. Cosenza et al. 1993; Ghobarah et al. 1999; Abbas 2011). Damage indices are based on either a single or combination of structural response parameters.

To have a structure capable of deforming in a ductile manner when subjected to several cycles of lateral loading, deformations concentrate in the region of the primary lateral force resisting mechanism (plastic deformation zone), wherein the demand of high deformability (curvature capacity) increases with the increase in the ductility demand. Consequently, length of this zone, which is one of the crucial aspects in the performancebased design, along with the distribution of curvature ductility $\left(\varphi / \varphi_{y}\right)$ would be useful to find out the impact of the studied parameters on the damage level, because the curvature $(\varphi)$ is dependent on steel strains. $\varphi$ is calculated using $\left(\varepsilon_{s t}-\varepsilon_{s c}\right) /\left(d-d^{\prime}\right)$, where $\varepsilon_{s t}$ and $\varepsilon_{s c}$ are the steel strains in the tension and compression sides of the loaded column, respectively (tensile strains are taken as positive and compression strains as negative), $d-d^{\prime}$ is the distance between the tension and compression steel pieces, and $\varphi_{y}$ is the curvature at first yield.

\subsection{Depth of yielding zone (Plastic deformation zone)}

At the ultimate achieved lateral drift of Specimen A, which is almost $4.2 \%$, length of the plastic deformation zone is defined for each of the studied cases in Table 1 based on the calculated distribution of curvature ductility through the column height. Fig. 8 shows the depth of the yielding zone as a ratio of the column height for all the studied cases. It is clear from the figure that depth of the yielding zone is in direct proportion to the value of $r$ of reinforcement used when it is in perfect bond to the surrounding concrete, where the normalized depth of the yielding zone could be changed from 0.41 to 0.54 by the increase of $r$ from 0.02 to 0.08 . In addition, it is evident that depth of the yielding zone is significantly affected by bond conditions, where the smallest depth of the yielding zone would be for columns with weak bond strength between ordinary rebars and the adjoining concrete, and this depth may possibly not change by the increase in the slippage of rebars.

\subsection{Curvature distribution}

While the yielding zone may locate in a small region at column base or extend beyond the normal range of the yielding zone based on the reinforcement type and its bond condition to the surrounding concrete, the worst case, i.e. with high damage level, still can not be defined. For example, the column typified $\left(0.08-S_{y}-2 f_{y}\right)$ has the greatest normalized depth of the yielding zone $(0.54>0.36$ of conventionally reinforced column) among the studied cases, however damage level would not be the worst based on the curvature distribution of both columns. Hence, distribution of curvature ductility is determined for all of the studied cases. 


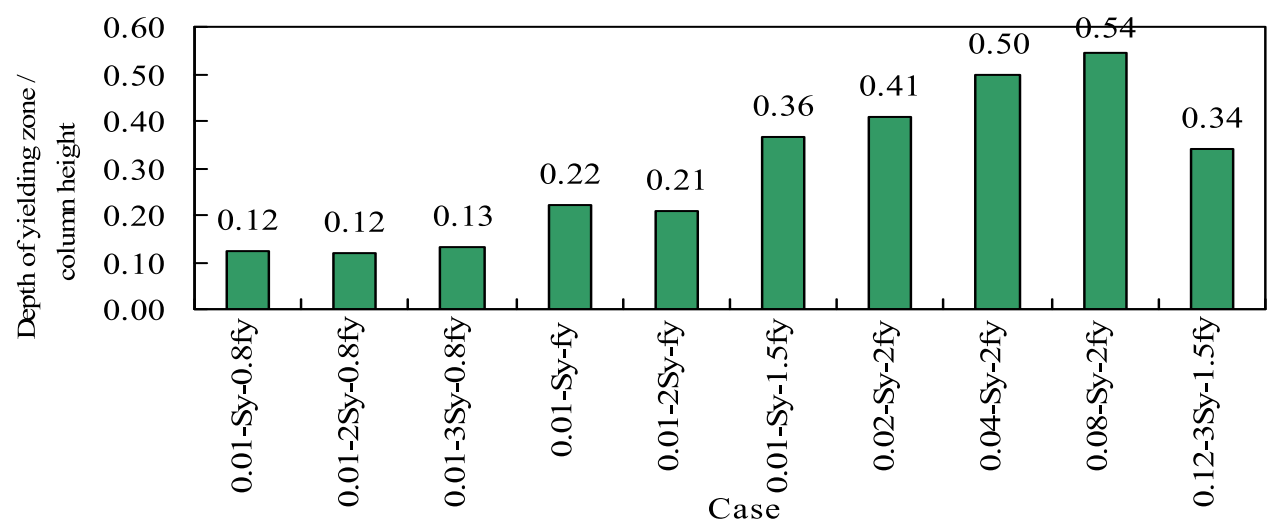

Fig. 8. Depth of the yielding zone of the studied cases at drift of $4.2 \%$ of column height

When bond strength is sufficient to assure the composite behavior between concrete and rebars, steel greatly contributes to the required deformability in the plastic zone. This is clear from Fig. 9 (a), where conventionally reinforced columns (case no. 6) exhibits high concentration of curvature ductility within the first $250 \mathrm{~mm}$ of the column height, i.e. curvature ductility is 32.3 at column base and reduces to 5.1 at $250 \mathrm{~mm}$. On the other hand, steel contribution to the required curvature ductility reduces when concrete-to-steel bond is weak. This can be seen from Fig. 9 (b) where curvature ductility reduces to $14.6 \%$ and $4 \%$ of that achieved by the conventionally reinforced column at its base when steel stresses at the ultimate slippage are $f_{y}$ and $0.8 f_{y}$, respectively, regardless of rebar ultimate slippage value. However, those columns can achieve the same level of the lateral drift of Specimen A as shown in Figs. $5 \& 6$, and this could be attributed to the increase in the contribution of column fixed-end rotation to lateral column deformation as shown in Fig. 10 (cases 1 to 6, listed in Table 1). In other words, when bond strength is weak, the reduction in steel contribution to lateral column deformation is compensated through the contribution of the fixed-end rotation due to rebars slippage, and this in turn reveals mitigation of damage in the plastic deformation zone.

Fig. 11 (a) details the distribution of curvature ductility of columns reinforced with rebars having bilinear ratio factors higher than that of ordinary rebars, e.g. rebars with $r=0.02$, 0.04 , and 0.08 , where perfect bond with the adjoining concrete are assumed for the three cases. It is clear that curvature ductility at column base and up until a height of $250 \mathrm{~mm}$ reduces by the increase in the value of $r$; nevertheless, out of this region the increase in $r$ adversely affects the distribution of curvature ductility: at $400 \mathrm{~mm}$ of column height, the change in $r$ from 0.02 to 0.04 and 0.08 increases curvature ductility from 1.8 to 4.1 and 3.8, respectively, and at $600 \mathrm{~mm}$ it increases from 0.97 to 1.16 and 1.3, respectively. Furthermore, in these three cases the curvature ductility demands within $100-\mathrm{mm}$ from the column base are smaller than those of the conventionally reinforced column (Fig. 9 (a)). In conclusion, using rebars with high level of strain-hardening may contribute to the mitigation of damage in the plastic hinge zone as a result of the redistribution of curvature ductility through the column height, and this propagation of yielding to a higher depth would compensate the demand of high deformability at column base to achieve a certain level of lateral drift. 

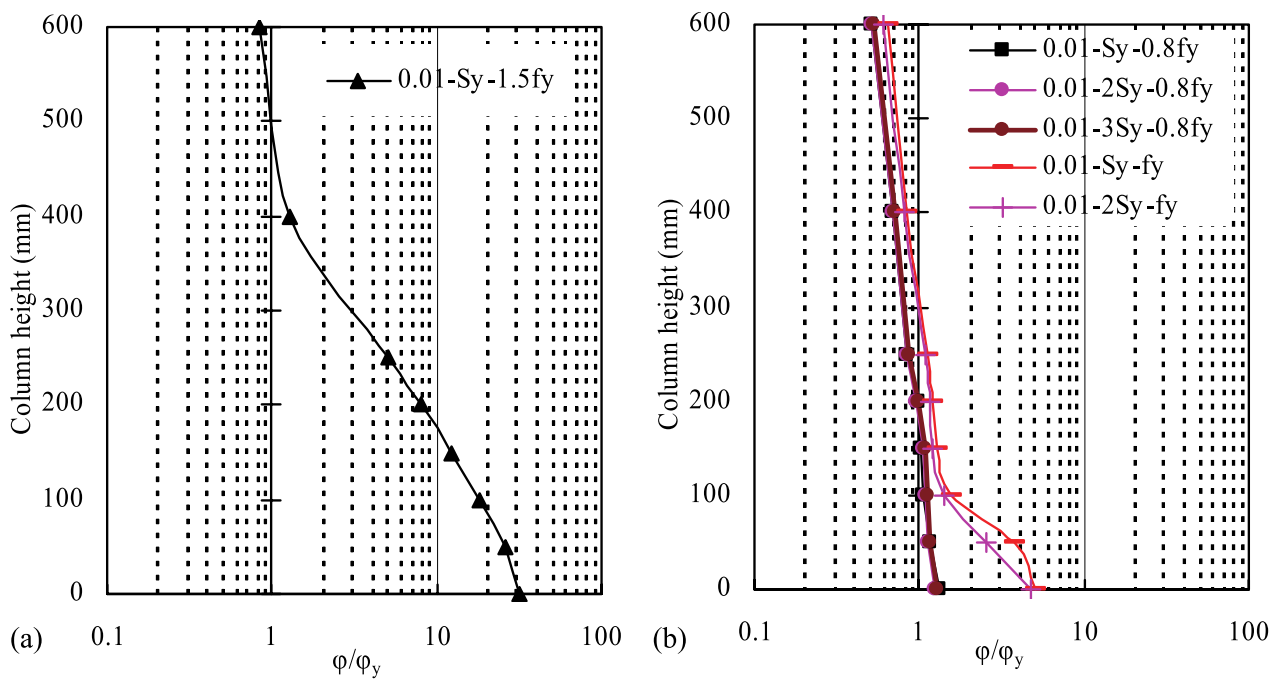

Fig. 9. The effect of bond properties between ordinary rebars $(r=0.01)$ and concrete on distribution of curvature ductility through column height at lateral drift of $4.2 \%$
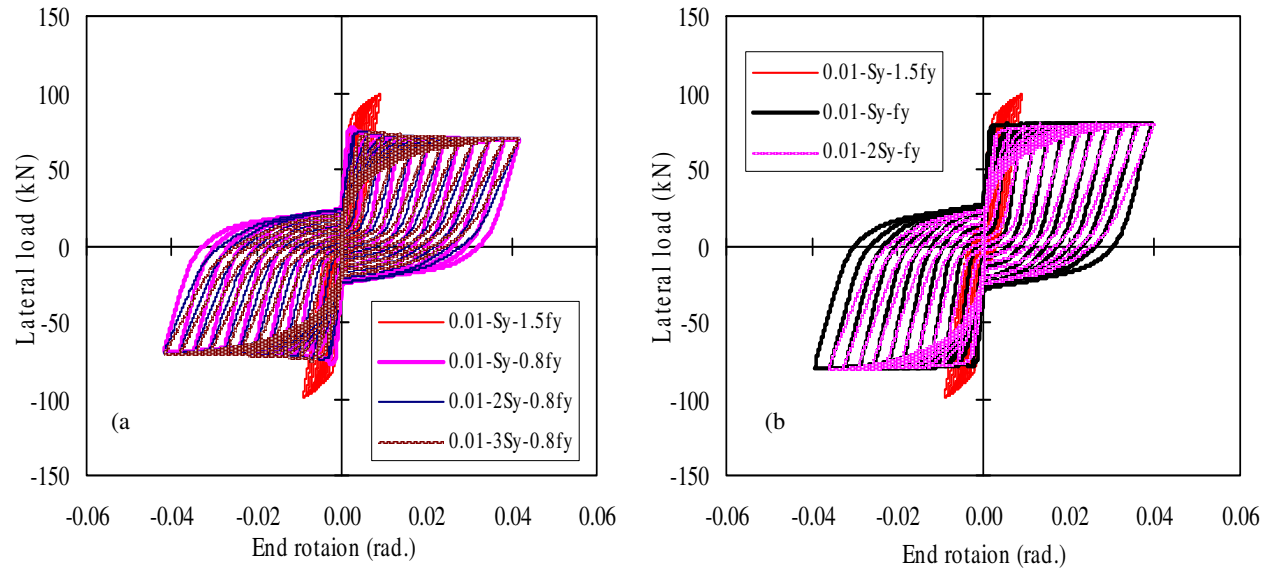

Fig. 10. Calculated fixed end-rotation versus lateral load 


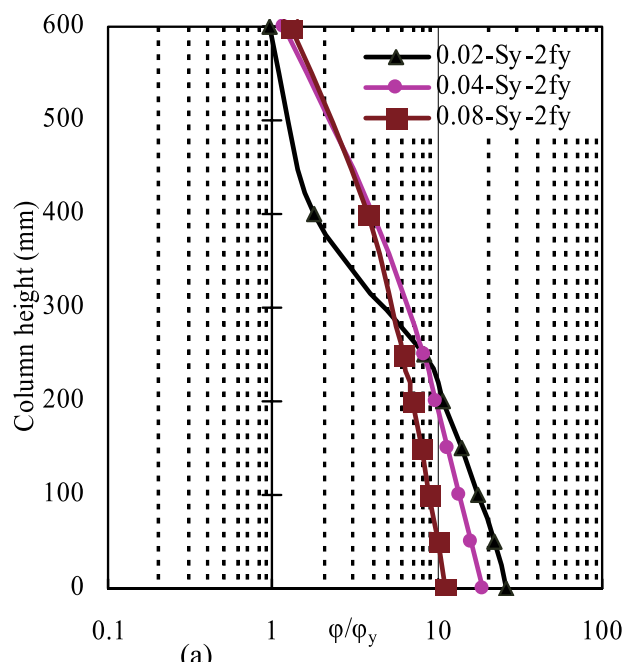

(a)

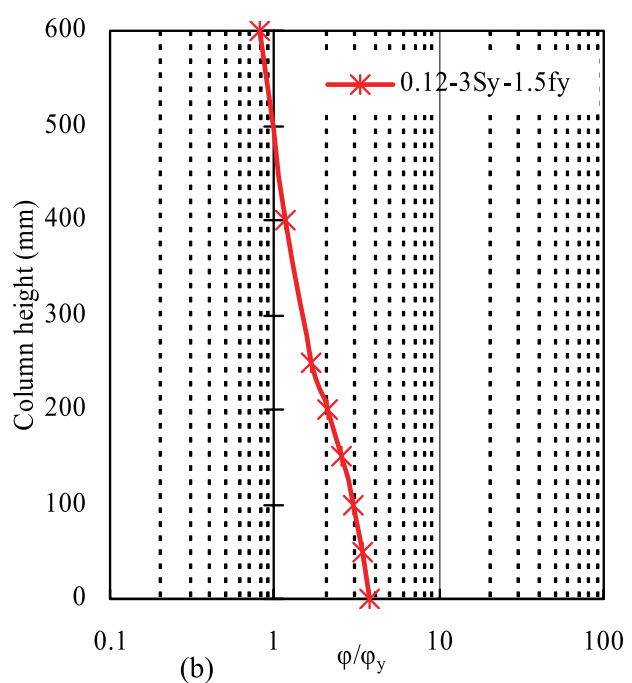

(b)

Fig. 11. The effect of bond properties between rebars $(r>0.01)$ and concrete on distribution of curvature ductility through column height at lateral drift of $4.2 \%$

The combined effect of both high bilinear ratio and bond capacity on the distribution of curvature ductility can be evaluated from Fig. 11 (b), where a well distribution of column curvature could be achieved. Curvature ductility is almost 3.78 at the interface section, is reduced to 2.12 and 1.17 at $200 \mathrm{~mm}$ and $400 \mathrm{~mm}$ from the column base, respectively, and ends at 0.8 at $600 \mathrm{~mm}$. Curvature distribution in this case also reveals the importance of using rebars with high strain-hardening performance, because when ordinary rebars loss their abilities of carrying load after yielding (cases number 4 \& 5 in Table 1) due to the weak bond strength, concentration of damage very close to column base is highly probable, see Fig. 9 (b).

Based on the aforementioned analytical results, contribution of steel deformations to lateral deformation of RC columns should be reduced to mitigate damage at the zone of plastic deformations and thus contribution of the fixed-end rotation, due to rebars slippage, is critical to achieve the desired drift demand. For conventionally reinforced structures, contribution of column fixed-end rotation could only guarantee mitigation of the concentrated damage in plastic deformation zones, namely, structures reinforced with rebars having elastic perfectlyplastic behavior or small bilinear factor $(r \leq 0.01)$, this contribution would be accompanied by a negative or zero post-yield stiffness behavior, Fig.6 (a\&b). However, reinforcing structures with bond-controlled rebars having high bilinear ratio factor would be a reasonable system to have a damage-free recoverable structure. Because structure might be able to continue carrying load in the inelastic stage and both damage level and residual deformations could be controlled.

\section{Experimental evaluation of recoverability of $\mathrm{RC}$ bridge columns reinforced with bond-controlled rebars and SFCBs}

In order to verify the analytical findings, experimental results of columns reinforced with unbonded deformed bars in plastic hinge zone (Kawashima et al., 2001) and those with bond-controlled reinforcements (Pandey \& Mutsuyoshi, 2005) are restudied here from the 
view point of the required recoverability. Furthermore, two columns reinforced with SBFCBs and SCFCBs were tested by Fahmy et al. (2010) to examine the effect of high strainhardening behavior of reinforcement used on the required recoverability. Reinforcements of both specimens were in normal bond conditions to the surrounding concrete.

\subsection{Bridge columns reinforced with unbonded deformed bars}

To enhance ductility of RC bridge columns, Kawashima et al. (2001) conducted an experimental study on scale-model RC columns reinforced with ordinary deformed bars, which were unbonded at the plastic hinge zone. Different unbonding lengths were considered in their study, e.g. $200 \mathrm{~mm}, 400 \mathrm{~mm}$, and $600 \mathrm{~mm}$ were the unbonded lengths in Specimens B, C, and D, (Fig. 12, and Table 2), respectively. The tested specimens had square cross-section of $400 \times 400 \mathrm{~mm}$ and $1450-\mathrm{mm}$-height. In view of the results of Kawashima et al. (2001), the required recoverability of unbonded RC columns are examined in this study.

The envelopes of the measured force-drift relationships of the three unbonded specimens are shown in Fig. 13. The curves are the average of the envelopes for the push-and-pull loadings. Additionally, for comparison, the measured force-drift relationship of Specimen A is superimposed on the same figure. It is evident from Fig. 13 that the increase of the unbonded length is accompanied by a decrease in the elastic stiffness, reduction of the achieved ultimate strength, and diminishing of post-yield stiffness.
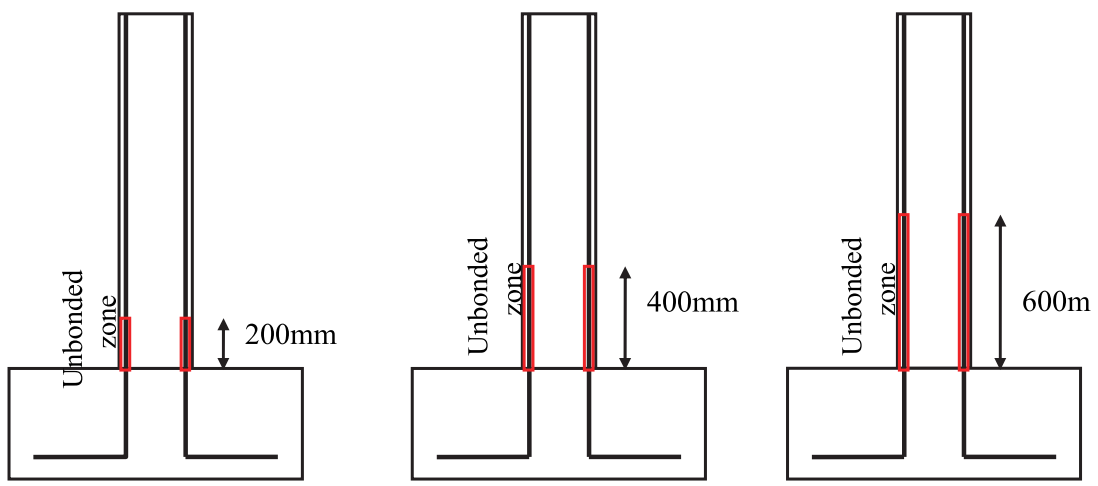

Fig. 12. Schematic details of the unbonded length of RC bridge columns

\begin{tabular}{|c|c|c|c|c|c|c|c|}
\hline Author & Sample & 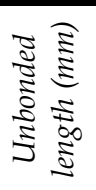 & $\begin{array}{l}\text { Axial } \\
\text { Load, } \\
\text { ratio } \\
(\%)^{a}\end{array}$ & $\begin{array}{l}\text { Main } \\
\text { steel }\end{array}$ & $v^{8} \sum^{E}$ & $\begin{array}{c}\text { Yield } \\
\text { stress of } \\
\text { main } \\
\text { steel, } \\
(\mathrm{MPa})\end{array}$ & $\begin{array}{c}\text { Yield } \\
\text { stress of } \\
\text { lateral } \\
\text { steel, } \\
(\mathrm{MPa})\end{array}$ \\
\hline \multirow{3}{*}{$\begin{array}{l}\text { Kawashima et al. } \\
\text { (2001) }\end{array}$} & Specimen B & 200 & 4.2 & 12 D13 & 23.6 & 367 & 376 \\
\hline & Specimen C & 400 & 4.1 & 12 D13 & 24.6 & 367 & 376 \\
\hline & Specimen D & 600 & 4.2 & 12 D13 & 23.5 & 367 & 376 \\
\hline
\end{tabular}

a axial load ratio $=\left((\right.$ axial load $\left.) /\left(A_{g} . f_{c o}^{\prime}\right)\right)$, where $A_{g}$ is the gross section area.

D13 = deformed bar with diameter of $13 \mathrm{~mm}$

Table 2. Details, dimensions, and material properties of unbonded RC columns 
Residual drift ratios verses column lateral drift ratios are plotted in Fig. 14 for the three unbonded specimens and the control one. This figure shows that there is a close similarity in the relation between the column drifts and the corresponding residual deformations for the four columns, which reveals that unbonding of deformed rebars at the plastic hinge zone with any length could not assure the alleviation of column residual deformations.

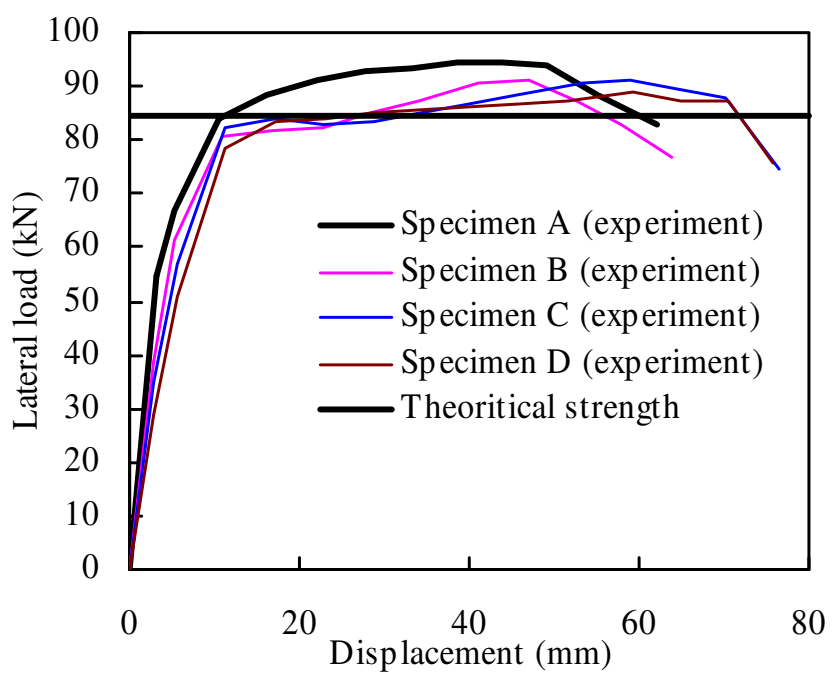

Fig. 13. Skeleton curves of the hysteretic responses of columns reinforced with bonded and unbonded deformed bars

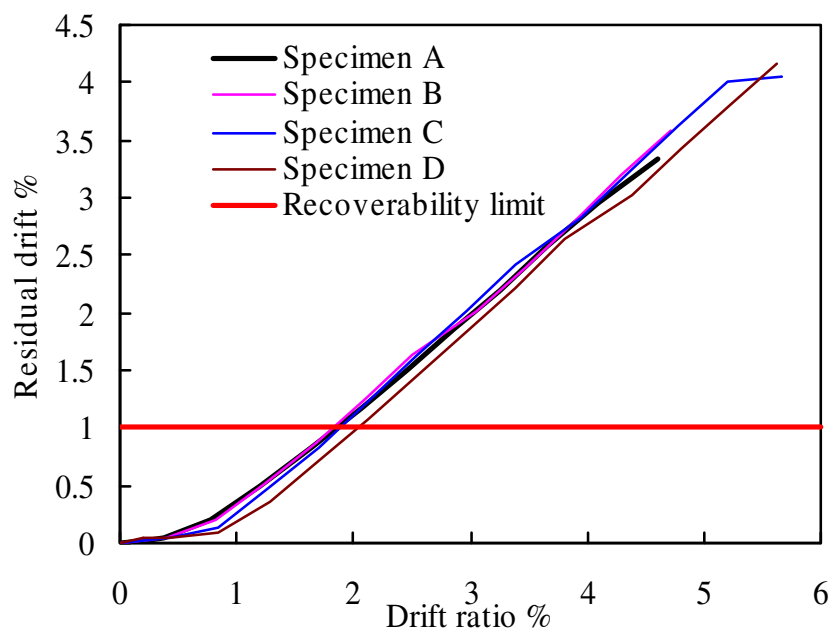

Fig. 14. Residual deformations of columns reinforced with bonded and unbonded deformed bars 


\subsection{Bridge columns reinforced with bond-controlled rebars}

An experimental investigation was carried out by Pandey and Mutsuyoshi (2005) to examine how controlling the bond of the longitudinal reinforcements can improve seismic performance factors, such as shear strength and ductility, of RC structures. Results of three of the tested columns (C-1, C-6, and C-7) are examined here to find the effects of surface characteristics of rebars used and also bond conditions of steel-to-concrete on the required recoverability: columns C-1 and C-6 were reinforced with DSBs and RSBs (round steel bars), respectively, but column C-7 was reinforced with RSBs, which had been coated with grease to further reduce bond strength through $800 \mathrm{~mm}$ length. Details of those columns are given in Table 3.

\begin{tabular}{|c|c|c|c|c|c|c|c|c|c|}
\hline Author & Sample & 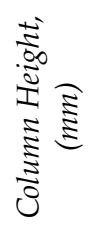 & 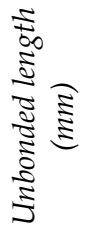 & $\begin{array}{l}\text { Axial } \\
\text { Load, } \\
\text { ratio } \\
(\%)^{a}\end{array}$ & $\begin{array}{l}\text { Main } \\
\text { steel }\end{array}$ & $\begin{array}{c}\text { Transverse } \\
\text { steel } \\
\text { (Size and } \\
\text { spacing, } \mathrm{mm} \text { ) }\end{array}$ & 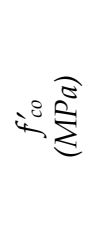 & $\begin{array}{c}\text { Yield } \\
\text { stress } \\
\text { of main } \\
\text { steel, } \\
(\mathrm{MPa})\end{array}$ & $\begin{array}{c}\text { Yield } \\
\text { stress } \\
\text { of } \\
\text { lateral } \\
\text { steel, } \\
(\mathrm{MPa})\end{array}$ \\
\hline \multirow{3}{*}{$\begin{array}{l}\text { Pandey and } \\
\text { Mutsuyoshi } \\
\text { (2005) }\end{array}$} & C-1 & 1050 & ---- & 2.7 & 12 D16 & D6 at 150 & 36.4 & 396.4 & 426.7 \\
\hline & C-6 & 1050 & --- & 2.6 & 12 Ф16 & D6 at 150 & 39.21 & 298.6 & 426.7 \\
\hline & C-7 & 1050 & 800 & 2.4 & $12 \Phi 16$ & D6 at 150 & 42.52 & 298.6 & 426.7 \\
\hline
\end{tabular}

a axial load ratio $=\left((\right.$ axial load $\left.) /\left(A_{g} . f_{c o}^{\prime}\right)\right)$, where $A_{g}$ is the gross section area.

$\mathrm{D} 16=$ deformed bar with diameter of $16 \mathrm{~mm}$; and $\Phi 16=$ round bar with diameter of $16 \mathrm{~mm}$.

Table 3. Details, dimensions, and material properties of bond-controlled RC columns

Because the lateral response of any of the investigated columns differs from that of others, the effect of the studied parameters on the achieved post-yield stiffness was evaluated as shown in Fig. 15, where average drifts of pull-and-push excursions of loading are plotted in relation to the corresponding column lateral strengths $(P)$ divided by the theoretical strength $\left(P_{i}\right)$. As a result of coating RSBs with grease, elastic stiffness of column C-7 was the smallest among the examined columns, Fig. 15. On the other hand, replacement of DSBs with RSBs slightly affected the elastic stiffness of column C-6, and it could not alter the shear failure mode of column C-1 to the ductile failure mode of column C-7, which was due to crushing and spalling of the concrete cover, followed by yielding of the longitudinal bars at the column-footing joint. In all cases shown in Fig. 15, negative post-yield stiffness is the performance in the inelastic stage, where the greatest deterioration of strength appeared in column C-1.

Relationship between column drifts and residual drifts is depicted in Fig. 16 for the columns C-1, C-6, and C-7. As is seen from Fig. 16, residual deformations of columns C-1 and C-6 are the same at any lateral drift, and their drifts at the recoverability limit are almost identical. This means that the use of RSBs in place of DSBs has no impact on column residual deformations. On the other hand, a favorable mitigation of column residual deformations was for column C-7 reinforced with unbonded RSBs. Column C-7 was capable of staying recoverable until lateral drift of $3.05 \%$, which is almost 1.5 times the drift of column C-6 at the recoverability limit. 
Although unbonding of DSBs at plastic hinge zone had no effect on column residual deformations, Fig. 14 and 16, it is interesting to stress on this finding which would help in realizing how could be the residual deformations controlled through the bond conditions between reinforcement and the surrounding concrete. When DSBs or RSBs are unbonded to the surrounding concrete, rigid body rotation due to rebar slippage would contribute to column lateral deformation and thus contribution of steel greatly reduces, and this was acknowledged in the study of Kawashima et al. (2001) through the measurements of steel strain at the plastic hinge zone, where strains of unbonded rebars were much lower than the counterpart in conventional RC columns. Despite the reduction of steel deformations, column residual deformations did not significantly change, particularly, when longitudinal reinforcement used was DSBs, and this can be attributed to partial unbonding of the DSBs, i.e. length of the unbonded zone, and characteristics of rebar surface. That is, owing to the interlocking of DSBs ribs of the bonded regions with the surrounding concrete, rebar cannot return to its former place after slippage. Therefore, unbonding of RSBs with grease coating for a length of $\sim 0.76$ of column height (column C7) increased the opportunity of limiting the residual fixed-end rotation and in turn the permanent deformations. In the study of Pandey and Mutsuyoshi (2005), it was reported that unbonding of most column height is an appropriate technique to avoid initiation of flexural cracks from the bonded regions. Consequently, mitigation of residual deformations of bond-controlled RC columns is dependent on the geometry of rebar surface as well as the length of the bonded regions.

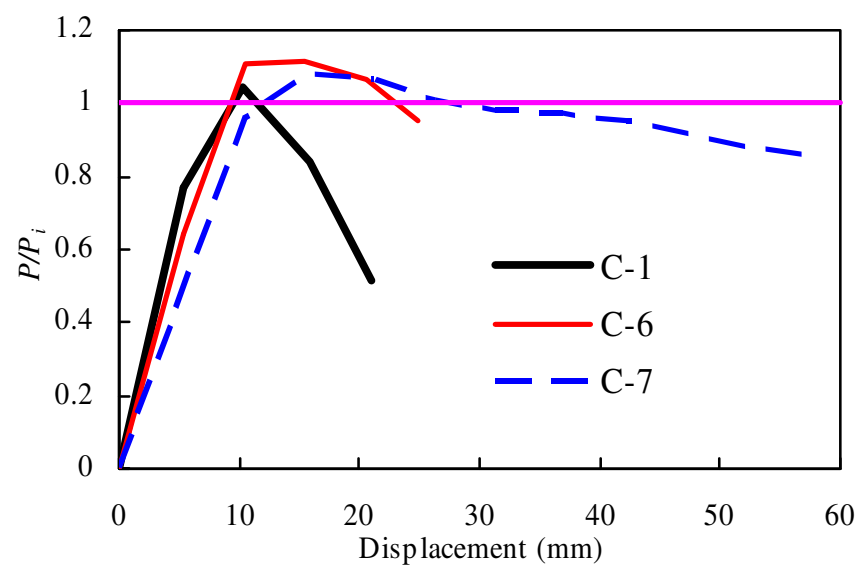

Fig. 15. Skeleton curves of the hysteretic responses of columns reinforced with bonded deformed bars and bonded and unbonded round bars 


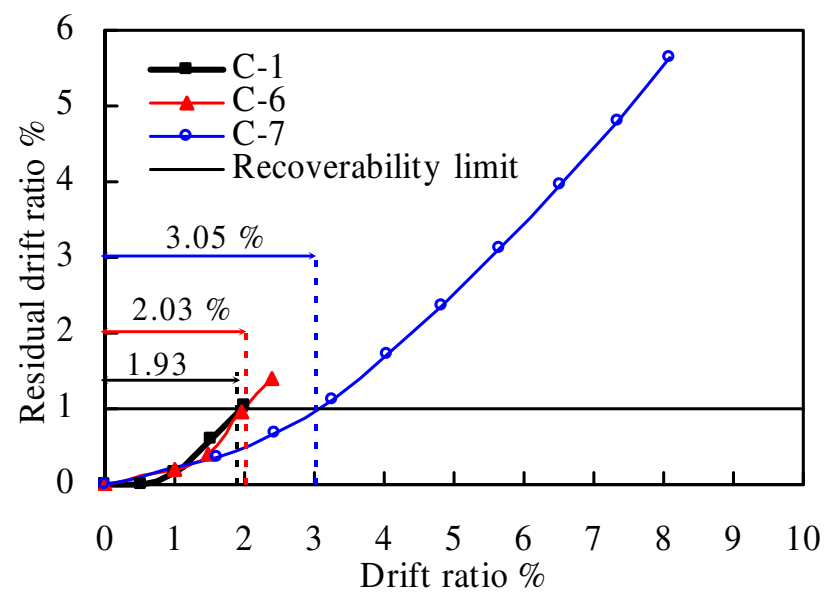

Fig. 16. Residual deformations of columns reinforced with bonded deformed bars and bonded and unbonded round bars

\subsection{Bridge columns reinforced with steel fiber composite bars (SFCBs)}

The results of this study are treated in a longer length in the study of Fahmy et al. (2010). Here, the hysteretic responses of the tested three columns are given to verify the possibility of enhancing recoverability of RC bridges using rebars with high level of strain-hardening as longitudinal reinforcement in place of ordinary rebars. Fig. 17 shows the results of three tested columns (CS14, CS10-C40 and CS10-B30), where the first column was reinforced with twelve deformed rebars with elastic perfectly-plastic behavior and the other columns were reinforced with steel fiber composite bars ( $r$ is over 10\%). It is evident from Fig. 17 that conventionally reinforced column was able to achieve lateral drift until $30 \mathrm{~mm}$ without any significant lose in the lateral capacity. However, after $\sim 21 \mathrm{~mm}$ later displacement $(1.91 \%$ lateral drift ratio) the column fell in the irrecoverable stat. on the other hand, the results of the other two columns (CS10-C40 and CS10-B30) showed recoverable performance till lateral drifts of $3.06 \%$ and $3.16 \%$, which correspond to $10.2 \%$ and $5.9 \%$ drop in the achieved ultimate strengths, respectively. However, due to the good bond between SFCBs and the adjoining concrete, Fig. 18 reveals extension of the plastic zone of column CS10-B30 beyond the counterpart in the conventionally reinforced column: depth of the damaged zone was almost 25\% of the column height for the columns CS14 and 31\% for CS10-B30, respectively.

Overall, the agreement found between all the addressed experimental results and the theoretical findings is acceptable. For instance, the decrease in the slope of both column elastic and post-yield stiffnesses due to poor bond qualities between ordinary rebars and the surrounding concrete is evident in the experimental results of Kawashima et al. (2001) and Pandey \& Mutsuyoshi (2005), Figs. 13 and 15. Moreover, the enhancement in the inelastic stage with the existence of post-yield stiffness was successfully achieved by columns reinforced with SFCBs. The analytical results showed that column residual deformations could be reduced when rebars slippage at yielding increases or rebars used have high level of the strain-hardening, and both effects are validated by the results of column C-7 reinforced with RSBs coated with grease (Fig. 16) and the results of the columns CS10-C40 and CS10-B30 reinforced with SFCBs, respectively, see Fig. 17. 

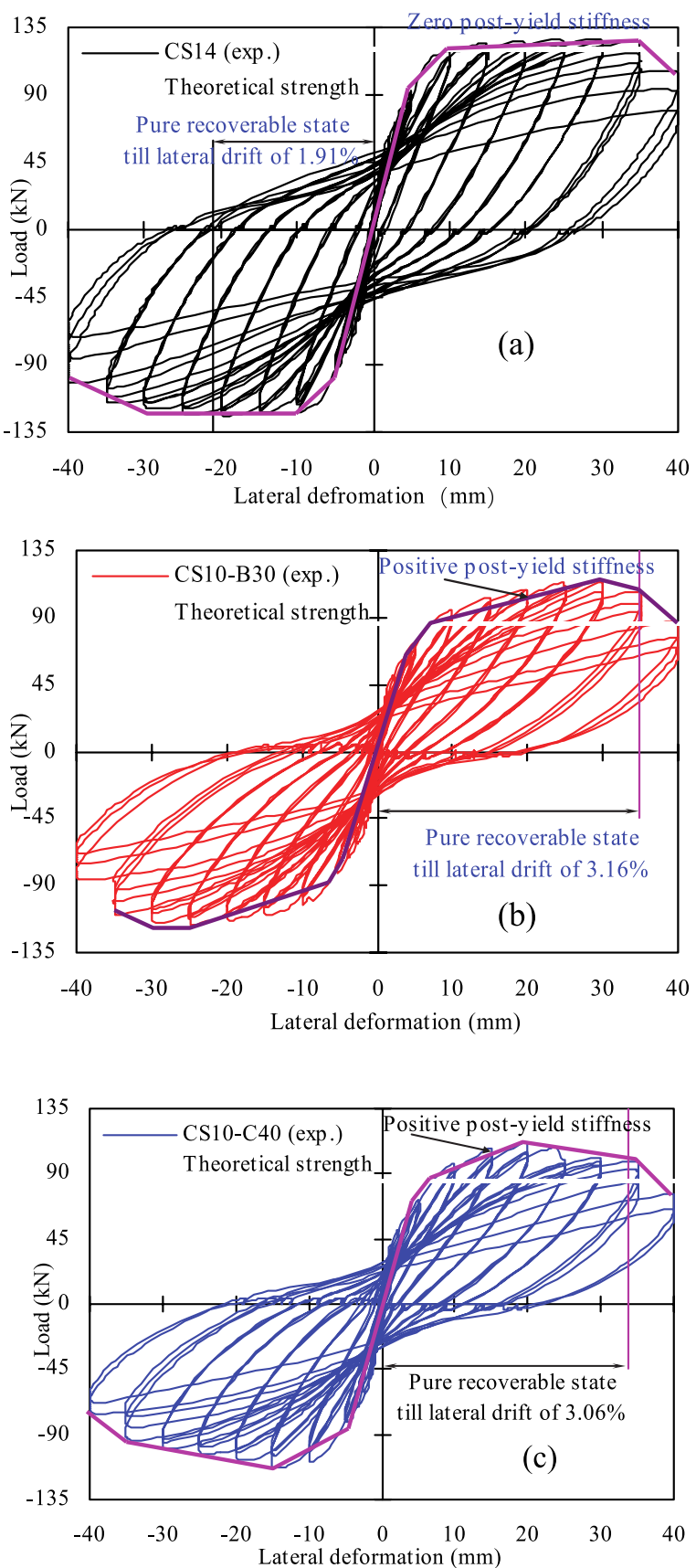

Fig. 17. Measured hysteretic lateral responses of the columns (a) CS14, (b) CS10-B30, and (c) CS10-C40 


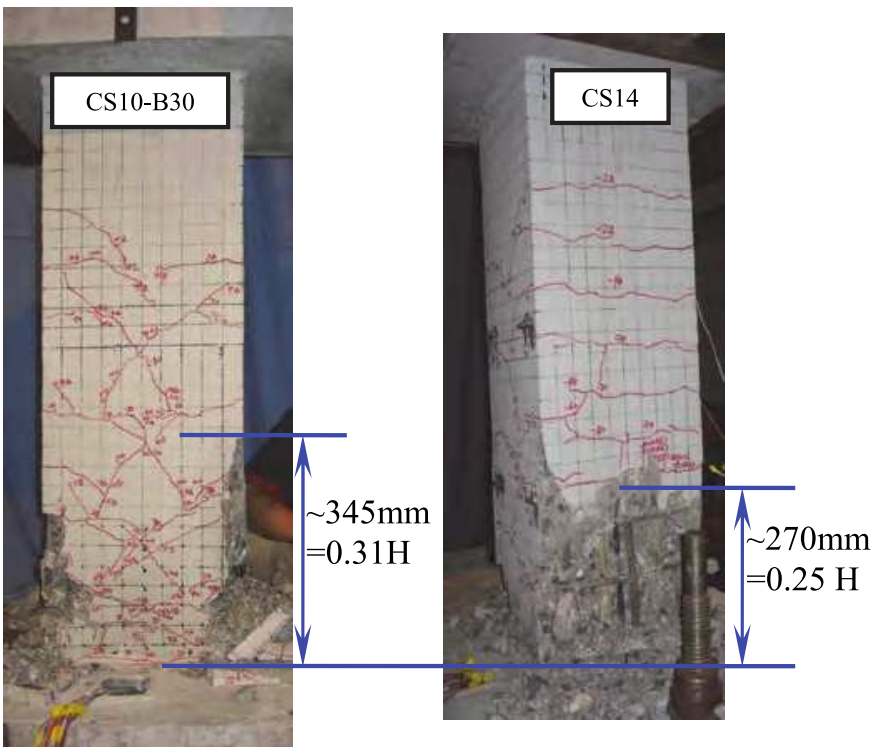

Fig. 18. Depth of damaged zone of the columns (a) CS10-B30 and (b) CS14

In conclusion, recoverable performance of RC columns lying in high seismicity regions can not be guaranteed with bond-controlled techniques using DSBs or RSBs. While using unbonded DSBs or RSBs would mitigate the concentration of damage at plastic hinge regions, bonded regions limit the probability of residual deformation mitigation. Moreover, unbonded columns hardly can achieve the theoretical strength with a negative or zero postyield stiffness performance in the inelastic stage. On the other hand, due to the promising performance of the innovative rebars (SFCBs), it is highly desirable to further study the effect of bond conditions on the recoverability of columns reinforced with SFCBs.

\section{Analytical study on RC columns reinforced with bond-controlled SFCBs}

Fig. 1 shows that the inner core ribbed rebar is first looped around with bundles of continuous fibers roving to fill up the space between its ribs, such that bond strength is guaranteed with the outer longitudinal fibers. This figure also shows that there is a spiral distribution of resin ribs along the SFCB. The main function of those ribs is to ensure the bond performance between a SFCB and the surrounding material, such as concrete, allowing SFCBs to achieve the designed level of strength. For instance, ribs with adequately designed spacing and height would lead SFCBs to approach their ultimate strength; however, in case ribs spacing is wide and the height is undersized, rebars may fail to continue to carry additional load until approaching the designed strength level. Besides, slippages of SFCBs at both yielding and maximum achieved strength depend on the applied bond technique. Consequently, five cases of RC columns reinforced with SFCBs are studied (Table 4), where four cases examine the effect of the achieved strength of SBFCBs on the performance of RC bridge columns. The last case (case no. 5) considers the effect of additional slippage of SFCBs when the ultimate strength is greatly affected by bond conditions, i.e. merely $70 \%$ of the ultimate strength could be achieved. 


\begin{tabular}{ccccc}
\hline Case & \multicolumn{5}{c}{ Bond properties } \\
\cline { 2 - 5 } & $\begin{array}{c}S_{y} \\
(\mathrm{~mm})\end{array}$ & $\begin{array}{c}\sigma_{y} \\
(\mathrm{MPa})\end{array}$ & $\begin{array}{c}S_{u} \\
(\mathrm{~mm})\end{array}$ & $\begin{array}{c}\sigma_{u} \\
(\mathrm{MPa})\end{array}$ \\
\hline 1 & $S_{y}$ & $f_{y}$ & $S_{u}$ & $f_{u}$ \\
2 & $S_{y}$ & $f_{y}$ & $S_{u}$ & $0.9 f_{u}$ \\
3 & $S_{y}$ & $f_{y}$ & $S_{u}$ & $0.8 f_{u}$ \\
4 & $S_{y}$ & $f_{y}$ & $S_{u}$ & $0.7 f_{u}$ \\
5 & $2 S_{y}$ & $f_{y}$ & $2 S_{u}$ & $0.7 f_{u}$ \\
\hline
\end{tabular}

Table 4. Studied bond properties of column reinforced with SFCBs

The studied column has square cross-section of $300 \times 300 \mathrm{~mm}$ and $1300-\mathrm{mm}$-tall. It is typified CS10-B30 and reinforced with twelve SBFCB, Table 5. The concrete compressive strength is $\sim 38 \mathrm{MPa}$. The columns are analyzed under the effect of constant axial load (12\% of column axial strength) and reversed cyclic lateral load. Under normal bond condition, a column with these given details was experimentally tested by Fahmy et al. (2010) with another column typified CS10-C40, where its longitudinal reinforcement was twelve SCFCB, Table 5.

\begin{tabular}{ccccccc}
\hline Type & $\begin{array}{c}\text { Diameter } \\
(\mathrm{mm})\end{array}$ & $\begin{array}{c}\text { Elastic } \\
\text { modulus } \\
\left(\mathrm{E}_{1}\right)(\mathrm{GPa})\end{array}$ & $\begin{array}{c}\text { Yield } \\
\text { strength } \\
(\mathrm{MPa})\end{array}$ & $\begin{array}{c}\text { Post-yield } \\
\text { stiffness } \\
\left(E_{2}\right),(\mathrm{GPa})\end{array}$ & $\begin{array}{c}\text { Ultimate } \\
\text { strength } \\
(\mathrm{MPa})\end{array}$ & $E_{2} / E_{1}(\%)$ \\
\hline Ф10+30B & 13.2 & 142 & 312.4 & 16.6 & 691.3 & 11.7 \\
$\begin{array}{c}\text { (SBFCB }) \\
\Phi 10+40 \mathrm{C}\end{array}$ & 12.9 & 155.5 & 342.2 & 30.2 & 641.8 & 19.7 \\
$\begin{array}{c}(\mathrm{SCFCB}) \\
\Phi 10\end{array}$ & 10 & 200 & 420 & - & 480 & - \\
\hline
\end{tabular}

Table 5. Properties of SFCB and ordinary rebars

Figure 19 shows the effect of bond properties on both column post-yield stiffness (its slop and end point) and residual deformations. For instance, with the assumption of extremely sufficient bond strength between SFCBs and the adjoining concrete, Figure 19 (a) shows the highest achieved inelastic stiffness which ends at lateral drift of $40-\mathrm{mm}$ (due to rupture of the outer basalt fibers) with the minimum residual deformations. But, when the composite behavior between SBFCBs and surrounding concrete can not assure the development of the ultimate strength of SFCBs, the inelastic hysteretic response after column yielding would be divided to two parts: the first shows that the column can still carry the load after the SBFCBs yield and hardening behavior has been exhibited; and the second part demonstrates a zero post-yield stiffness, which starts by the end of the hardening zone. As is clear from Figs. 19 (a-e), the slop of the post-yield stiffness and its end point is dependent on the bond conditions. In addition, the controlled increase in slippage of SFCBs would assist in further mitigation of residual deformations, Figs. 19 $(\mathrm{d} \& \mathrm{e})$. 

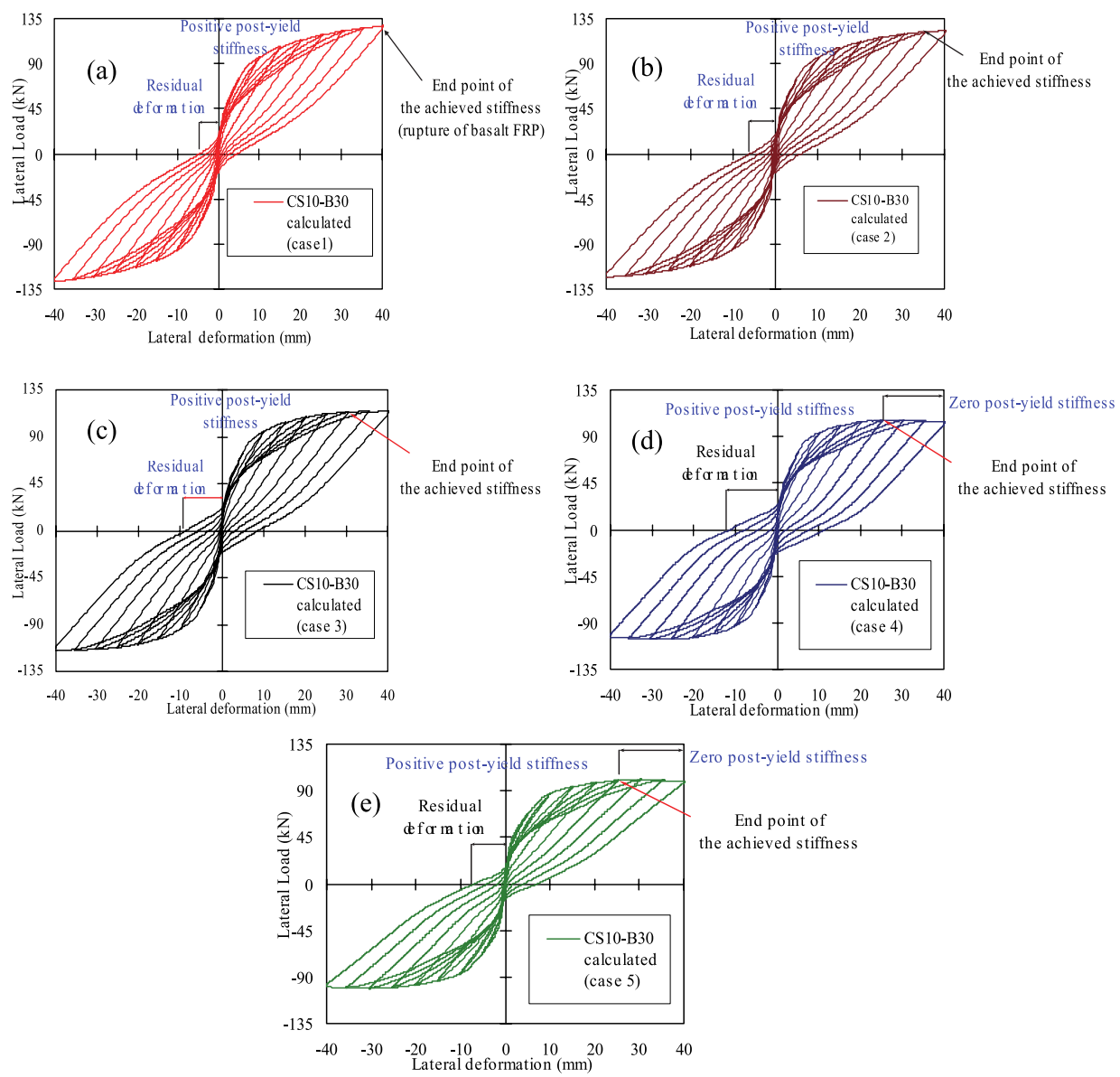

Fig. 19. Bond effect on performance of RC column reinforced with SBFCBs

\section{Summary and conclusions}

The demand for efficient and effective damage-controllable systems has received strong attention in the last decade, where the main goal is the limitation of the damage at plastic hinge zones along with substantial mitigation of the static residual deformations. Since bond between longitudinal reinforcement and concrete is a key factor controlling structural performance of reinforced concrete (RC) structures, here a study was conducted to examine the effect of alternating the bond conditions between longitudinal reinforcement and concrete on the performance of RC columns. Effects of different conditions of concrete-tosteel bond on the elastic and post-yield stiffnesses, residual deformations, and damage level of $\mathrm{RC}$ bridge columns reinforced with rebars having different strain-hardening levels were determined. For ordinary steel bars RSBs and DSBs, the study showed that damage of plastic hinge zone is mitigated provided that reinforcement is completely unbonded from the surrounding concrete. Also, the study revealed that residual deformation of columns 
reinforced with RSBs can be mitigated only if the unbonded zone represents most of the column height. Despite these encouraging findings, unbonded columns could barely achieve the theoretical strength with zero or negative post-yield stiffness in the inelastic stage. That is, quick recovery of of RC columns reinforced with unbonded DSBs or RSBs can not be guaranteed, which limits the practical application of this technique in RC bridge columns lying in high seismicity zones. Since RC column reinforced with SBFCBs distinctly outperforms its RC counterpart, bond-based damage-controllable system using SBFCBs could be applied for structures reinforced with the innovative rebars, where slope and end point of the achieved post-yield stiffness can be controlled. In addition, both residual deformations and damage level at plastic hinge zone could be limited.

\section{References}

ACI Committee 318. Building code requirements for structural concrete (ACI 318-08) and commentary (318R-08). American Concrete Institute (ACI) 2008, Farmington Hills, Mich., 430 pp.

Cosenza, C.; Manfredi, G. \& Ramasco, R. (1993). The use of damage functionals in earthquake engineering: a comparison between different methods. Earthquake Eng. Struct. Dyn., Vol. 22, pp. 855-868.

Fahmy, M.F.M.; Wu, Z.S., Wu, G. \& Sun, Z.Y. (2010). Post-yield stiffnesses and residual deformations of $\mathrm{RC}$ bridge columns reinforced with ordinary rebars and steel fiber composite bars. Journal of Engineering Structures, Vol.32, pp. 2969-2983.

Ghobara, A.; Abou-Elfath, H. \& Biddah, A. (1999). Response-based damage assessment of structures. Earthquake Eng. Struct. Dyn., Vol. 28, pp. 79-104.

JSCE Earthquake Engineering Committee (2000). Earthquake resistant design codes in Japan. Japan Society of Civil Engineers (JSCE), Tokyo, Japan, 150 pp.

Kawashima, K.; Hosoiri, K.; Shoji, G., \& Sakai, J. (2001). Effects of unbonding of main reinforcements at plastic hinge region on enhanced ductility of reinforced concrete bridge columns. Structural and Earthquake Engineering, Proc. JSCE, 689/I-57, pp. 4564.

Mazzoni, S; McKenne, F; Scott, MH; Fenves, GL, et al. Open System for Earthquake Engineering Simulation User Manual version 2.1.0. Pacific Earthquake Engineering Center, University of California, Berkeley, CA, http://opensees.berkeley.edu/OpenSees/manuals/usermanual/

Moustafa, A. (2011). Damage-based design earthquake loads for single-degree-of-freedom inelastic structures. Journal of Structural Engineering (ASCE), Vol. 137, No.3, pp. 456467.

Pandey, GR \& Mustsuyoshi, H. (2005). Seismic performance of reinforced concrete piers with bond-controlled reinforcements. ACI Structural Journal, Vol.102, No.2, pp. 295304.

Park, R. \& Paulay, T. (1975). Reinforced concrete structures. John Wiley and Sons, 769pp.

Pettinga, D. ; Pampanin, S. ; Christopoulos, C. \& Priestley, N. (2006). Accounting for residual deformations and simple approaches to their mitigation. First European Conference on Earthquake Engineering and Seismology, Geneva, Switzerland.

Priestley, M.J.N.; Calvi, G.M. \& Kowalsky. (2007). Displacement-based seismic design of structures. IUSS Press, Pavia, 721pp. 
Saiidi, M.S. ; O’Brein, M. \& Sadrossadat-Zadeh, M. (2009). Cyclic response of concrete bridge columns using superelastic nitinol and bendable concrete. ACI Structural Journal; Vol.106, No.1, pp. 69-77.

Spacone, E.; Filippou, F. \& Taucer, F. (1996). Fiber beam-column model for nonlinear analysis of R/C frames-part II: applications. Journal of Earthquake Engineering and Structural Dynamics, Vol. 25, pp. 727-742.

Takiguchi, K. ; Okada, K. \& Sakai, M. (1976). Ductility capacity of bonded and unbonded reinforced concrete members. Proc. Architectural Institute of Japan. 249, pp. 1-11.

Wu, G. ; Wu, ZS. ; Luo, YB. ; Sun, ZY. \& Hu, XQ (2010). Mechanical properties of steel fiber composite bar (SFCB) under uniaxial and cyclic tensile loads. Journal of Materials in Civil Engineering, Vol. 22, No. 10, pp. 1056-1066.

Zhao, J. and Sritharan, S. (2007). Modeling of strain penetration effects in fiber-based analysis of reinforced concrete structures. ACI Structural Journal, Vol. 104, No.2, pp. 133-141. 


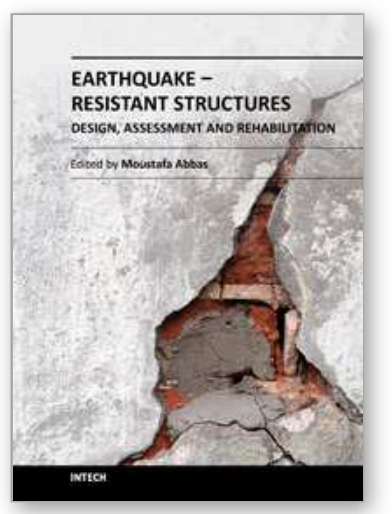

\section{Earthquake-Resistant Structures - Design, Assessment and Rehabilitation}

Edited by Prof. Abbas Moustafa

ISBN 978-953-51-0123-9

Hard cover, 524 pages

Publisher InTech

Published online 29, February, 2012

Published in print edition February, 2012

This book deals with earthquake-resistant structures, such as, buildings, bridges and liquid storage tanks. It contains twenty chapters covering several interesting research topics written by researchers and experts in the field of earthquake engineering. The book covers seismic-resistance design of masonry and reinforced concrete structures to be constructed as well as safety assessment, strengthening and rehabilitation of existing structures against earthquake loads. It also includes three chapters on electromagnetic sensing techniques for health assessment of structures, post earthquake assessment of steel buildings in fire environment and response of underground pipes to blast loads. The book provides the state-of-the-art on recent progress in earthquake-resistant structures. It should be useful to graduate students, researchers and practicing structural engineers.

\section{How to reference}

In order to correctly reference this scholarly work, feel free to copy and paste the following:

Mohamed F.M. Fahmy and Zhishen Wu (2012). Bond-Based Earthquake-Proof of RC Bridge Columns Reinforced with Steel Rebars and SFCBs, Earthquake-Resistant Structures - Design, Assessment and Rehabilitation, Prof. Abbas Moustafa (Ed.), ISBN: 978-953-51-0123-9, InTech, Available from: http://www.intechopen.com/books/earthquake-resistant-structures-design-assessment-and-rehabilitation/bondbased-earthquake-proof-of-rc-bridge-columns-reinforced-with-steel-rebars-and-sfcbs

\section{INTECH}

open science | open minds

\section{InTech Europe}

University Campus STeP Ri

Slavka Krautzeka 83/A

51000 Rijeka, Croatia

Phone: +385 (51) 770447

Fax: +385 (51) 686166

www.intechopen.com

\section{InTech China}

Unit 405, Office Block, Hotel Equatorial Shanghai

No.65, Yan An Road (West), Shanghai, 200040, China

中国上海市延安西路65号上海国际贵都大饭店办公楼 405 单元

Phone: +86-21-62489820

Fax: $+86-21-62489821$ 
(C) 2012 The Author(s). Licensee IntechOpen. This is an open access article distributed under the terms of the Creative Commons Attribution 3.0 License, which permits unrestricted use, distribution, and reproduction in any medium, provided the original work is properly cited. 